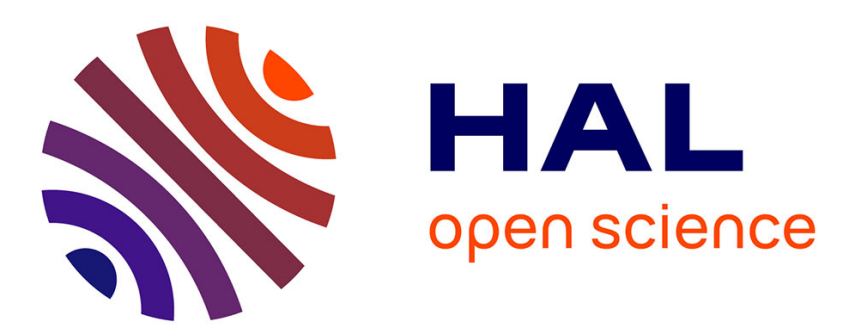

\title{
Les guerres parthiques de Démétrios II et Antiochos VII dans les sources gréco-romaines, de Posidonios à Trogue/Justin
}

Charlotte Lerouge-Cohen

\section{- To cite this version:}

Charlotte Lerouge-Cohen. Les guerres parthiques de Démétrios II et Antiochos VII dans les sources gréco-romaines, de Posidonios à Trogue/Justin. Journal des Savants, 2005, 2 (1), pp.217-252. 10.3406/jds.2005.1694 . hal-02460878

\section{HAL Id: hal-02460878 https://hal.science/hal-02460878}

Submitted on 30 Jan 2020

HAL is a multi-disciplinary open access archive for the deposit and dissemination of scientific research documents, whether they are published or not. The documents may come from teaching and research institutions in France or abroad, or from public or private research centers.
L'archive ouverte pluridisciplinaire HAL, est destinée au dépôt et à la diffusion de documents scientifiques de niveau recherche, publiés ou non, émanant des établissements d'enseignement et de recherche français ou étrangers, des laboratoires publics ou privés. 


\section{LES GUERRES PART'HIQUES DE DÉMÉTRIOS II ET ANTIOCHOS VII DANS LES SOURCES GRÉCO-ROMAINE, DE POSIDONIOS À TROGUE/JUSTIN}

Les Parnes, peuple nomade venu des steppes, envahissent en 239 av. J.-C. la Parthyène, petite satrapie séleucide du nord-est de l'Iran de laquelle ils tirent le nom de Parthes sous lequel on les désigne par la suite. Ce n'est qu'au II ${ }^{\mathrm{e}}$ siècle, sous le règne du grand roi Mithridate I ( I I I-I 38 av. J.-C.), qu'ils entament la série de conquêtes qui fait d'eux les maîtres de la quasitotalité de l'Orient antique : dans les années I40, Mithridate conquiert tout l'Iran et la plus grande partie du royaume gréco-bactrien à l'exception de la Bactriane proprement dite; il s'empare ensuite de la Babylonie ${ }^{\mathrm{I}}$. Les rois séleucides réagissent face à cette avance. En I40-I39, Démétrios II lance une campagne de reconquête qui finit mal : son armée est détruite et il est fait prisonnier chez les Parthes. Son frère Antiochos VII, dix ans plus tard ( I $30-^{3}$ I 29 av. J.-C.), emmène à son tour une armée au-delà de l'Euphrate afin de délivrer son frère et de récupérer les territoires conquis par les Arsacides, sans plus de succès : il est tué au cours d'une bataille. Après cet échec, les Séleucides renoncent à reconquérir les territoires qui leur ont échappé.

Sur les deux guerres de reconquête menées par les Séleucides contre les Parthes au II siècle av. J.-C., nous disposons, dans la tradition juive, de quelques lignes de I Macc. consacrées à Démétrios II (I Macc. r4, I-3; Ioo av. J.-C.). La tradition gréco-romaine est plus fournie, mais tardive. Le récit le plus long et le plus complet se trouve dans les Histoires Pbilippiques

I. Une tablette cunéiforme babylonienne datée de $\mathrm{I}_{4 \mathrm{I}}$ porte le nom d' "Arsacès ", nom générique de tous les rois parthes : voir A.T. OLMSTEAD, « Cuneiform Texts and Hellenistic Chronology ", Classical Pbilology, 32, 1937, p. I3. 
de 'Trogue Pompée, œuvre de l'époque d'Auguste que nous ne connaissons que dans la version abrégée qu'en a donné un certain Justin à la fin du $\mathrm{II}^{\mathrm{e}}$ siècle ou au $\mathrm{III}^{\mathrm{e}}$ siècle ${ }^{2}$; les autres sources sont constituées par des fragments des livres 33-34 de Diodore de Sicile et par quelques brèves mentions de Flavius Josèphe et d'Appien. Les auteurs de la tradition gréco-romaine se fondent cependant sur des sources plus anciennes : ils ne sont pas les premiers à avoir évoqué les Parthes ni les rapports entre Parthes et Séleucides, et dans leurs récits on retrouve l'écho de ceux de leurs prédécesseurs dont l'œuvre est perdue. Parmi ces prédécesseurs, un nom surnage : c'est celui du grand historien-philosophe Posidonios ( $135-5 \mathrm{x}$ av. J.-C.); les études de L. Santi-Amantini et E. Salomone ont prouvé que ses Histoires constituaient la source principale de Trogue/Justin pour les livres 36-39, à partir du moment où prend place dans les Histoires Pbilippiques le récit de la guerre de Démétrios 3 . On estime également que les récits de Flavius Josèphe et d'Appien sont fondés sur le texte de Posidonios, même si ces auteurs ne l'avaient probablement pas lu de manière directe mais à travers une source intermédiaire - Nicolas de Damas dans le cas de Josèphe.

La question que je me suis posée est celle de savoir s'il était possible, à travers ces textes et surtout à travers celui de Trogue/Justin, le plus long, de reconstituer la façon dont Posidonios lui-même racontait les guerres entre

2. Diverses dates ont été proposées pour la compilation, Justin étant par ailleurs totalement inconnu. Les récentes études de J.C. Yardley, traducteur des Histoires Philippiques, sur le vocabulaire de Justin le poussent cependant à affirmer avec une quasi-certitude que l'œuvre de Trogue Pompée a été compilée à la toute fin du II siècle ou au début du III siècle; la langue de Justin présente en effet de très importantes similitudes avec celle des auteurs de cette époque, et notamment avec celle de Quintilien. Voir R. DeVELIN et J. C. YARDLEY, Justin. Epitome of the Pbilippic History of Pompeius Trogus, traduction de J.C. Yardley avec une introduction et des notes de R. Develin, Atlanta, I994, p. 4 ; sur la langue de Trogue/Justin, J.C. YARDLEY, Justin and Pompeius Trogus. $A$ Study of the Language of Justin's Epitome of Trogus (Pboenix 4I), Toronto, 2003.

3. Justin indique dans sa préface que Trogue Pompée avait pour source des historiens grecs (voir Praef. 3 : "bistorici Graecorum »). Sur Posidonios et Trogue, voir les études de L. SANTIAmantinl, Fonti e valore storico di Pompeo Trogo (Iustin. 35 e 36), Gênes, 1972 et de E. SAloMONE, Fonti e valore storico di Pompeo Trogo (Iustin. XXXVIII 8, 2-40), Gênes, 1973. Les deux auteurs estiment que Trogue ne connaissait Posidonios qu'à travers un intermédiaire. Cette thèse ne me paraît cependant pas indispensable pour comprendre les distorsions que Trogue fait subir à Posidonios: rappelons-nous que nous ne connaissons Trogue que par l'abrégé qu'en a donné Justin! G. Forni et M.G. ANGeli-Bertinelli, dans "Pompeo Trogo come fonte di storia ", $A N R W$ II.30.2, 1982, p. I 298-I 362, résument l'état de la question des sources de Trogue/Justin pour chaque livre des Histoires Pbilippiques. 
Parthes et Séleucides. Peut-on faire la part de ce qui, dans les Histoires Philippiques, remonte à la source grecque et de ce qui est le fruit d'une intervention postérieure? La question, pertinente pour l'ensemble des Histoires Philippiques, l'est particulièrement à propos des récits de guerres mettant en scène des Parthes : on sait qu'en 53 av. J.-C., les Romains ont subi à Carrhes, aux mains des Parthes, une de leurs plus cuisantes défaites; ils entretiennent par la suite avec leurs voisins orientaux de constants rapports dans lesquels les phases hostiles alternent avec les phases pacifiques, les Parthes occupant toujours, à partir de l'époque d'Auguste et jusqu'à la fin du Haut-Empire, une place très importante dans le discours politique romain. Cette permanente actualité des Parthes ne vient-elle pas déformer les propos que l'on peut tenir à Rome sur les guerres opposant Parthes et Séleucides ? La question est compliquée par le fait que nous ne connaissons les Histoires Pbilippiques que par un abrégé plus tardif: si nous constatons une déformation romaine dans le récit des expéditions parthiques des Séleucides, comment savoir si elle provient de Trogue ou de Justin ? En bref, les récits des guerres entre Parthes et Séleucides reflètent-ils la pensée d'un Grec de la fin de l'époque hellénistique, d'un Romain de l'époque d'Auguste ou d'un Romain contemporain des Sévères ? Ce sont les questions auxquelles nous allons essayer de répondre ici, en analysant de façon très précise le texte de Trogue/Justin et en le confrontant avec les autres sources que nous avons à notre disposition et qui dérivent également de Posidonios ${ }^{4}$. Nous serons ainsi en mesure de reconstituer, ne serait-ce que partiellement, la vision posidonienne des guerres entre Parthes et Séleucides, et de mesurer l'évolution qui a pu avoir lieu par la suite sur ce sujet.

$$
* *
$$

Il est nécessaire d'abord de présenter l'œuvre historique de Posidonios de Rhodes, source supposée de Trogue dans les livres qui nous intéressent, et les parties de cette œuvre qui concernent les Parthes et les guerres entre Parthes et Séleucides.

4. J'ai été constamment guidée, dans ce travail fondé à la fois sur des fragments (ceux de Posidonios) et sur un abrégé, par les préceptes qu'énonce P. BRUNT sur l'utilisation de ce type de sources dans "On historical fragments and epitomes", CQ 30, 1980, p. 477"494. 
Posidonios de Rhodes, un des plus grands esprits du I ${ }^{\text {er }}$ siècle av. J.-C., philosophe stoïcien qui eut Cicéron parmi ses élèves et fut, d'après Strabon, l'ami de Pompée', auteur prolifique d'écrits dont ne subsistent que des lambeaux, avait rédigé entre autres des Histoires en 52 livres qui prenaient la suite de l'œuvre de Polybe et commençaient donc en $146^{6}$. Elles se prolongeaient, selon toute probabilité, jusqu'en 86 , date du dernier événement évoqué, et sont peut-être inachevées?. Nous disposons de deux moyens pour connaître cette ouvre : les fragments qui nous en sont parvenus; les livres 32-40 de la Bibliothèque Historique de Diodore de Sicile. Les fragments sont au nombre d'une bonne soixantaine, d'après l'édition de Posidonios qu'ont donnée L. Edelstein et I.G. Kidd en I972. Beaucoup de ces fragments ont été transmis par Athénée - ce qui est pour nous une chance, puisqu'on sait qu'Athénée transcrit fidèlement les passages qu'il cite; les autres se trouvent en majorité chez Strabon et Plutarque. Ils indiquent que Posidonios voyait l'histoire en moraliste ${ }^{8}:$ il fustigeait sévèrement les excès

5. Strabon II, $\mathrm{x}, 6$. Pour une biographie de Posidonios, voir M. LAFFranQue, Poseidonios. Essai de mise an point, Paris, 1964, p. 46-97.

6. C'est la Souda qui nous donne ces renseignements. Voir Edelstein-Kidd T. ra. J'ai utilisé pour cette étude l'édition des fragments de Posidonios de L. Edlestein et I.G. Kidd (abrégée E-K) : voir L. EDLESTEIN et I.G. KIDD, Posidonius I. The Fragments, Cambridge, 1972 ; I.G. KIDD, Posidonius II. The Commentary, Cambridge, 1986 (vol. I) et 1988 (vol. 2) ; ID., Posidonius III. The translation of the Fragments, Cambridge, 1999. Il existe également l'édition de F. JACOBY, FGrH 87, et une édition plus récente, celle de G. Theiler, Poseidonios. Die Fragmente. I. Texte; II. Erlaüterungen, Berlin, New York, 1982. Il me semble plus prudent cependant de continuer à utiliser l'édition Edelstein-Kidd, dont les auteurs ont adopté une méthode de sélection des fragments très rigoureuse : ils n'ont édité que les fragments dans lesquels le nom de Posidonios est cité. $G$. Theiler au contraire a inclus des passages d'autres historiens, comme Diodore, dont on sait qu'ils ont utilisé Posidonios, mais qui ne le citent pas : on peut dans ce cas se poser la question de savoir s'il s'agit vraiment de "fragments ". Voir l'introduction par I. G. KIDD du volume I des Fragments, ainsi que ID., "What is a Posidonian Fragment ", dans G. MosT éd., Collecting Fragments/Fragmente sammeln, Göttingen, 1997, p. 225-236.

7. Voir sur le point souvent discuté de la date jusqu'à laquelle se prolongeaient les Histoires la mise au point de I.G. KIDD, dans Posidonitus II (I). The Commentary, p. 277-280. Sur les Histoires, on peut lire également J. MaliTz, Die Historien von Poseidonios, Munich, 1983 ; H. STRASBURGER, "Poseidonios on Problems of Roman Empire», JRS, 55, 1965; A.D. Nock, "Posidonius ", JRS, 49, i95s.

8. Voir sur la question des rapports entre l'histoire de Posidonios et sa pensée philosophique et morale I.G. KIDD, « Posidonius as Philosopher-Historian », dans J. BARNES et M.T. GRIFFIN éd., Philosopbia Togata, vol. I, Oxford, 1998, p. 38-50. L'auteur résume ses conclusions dans Posidonius III, op. cit. (n. 6), p. 25-27. 
des souverains, notamment des rois hellénistiques dont il critiquait le goût pour le luxe et la débauche, et vantait les vertus et la frugalité des anciens Romains 9 . Il s'intéressait à la question du pouvoir et des rapports entre dominants et dominés, qu'il s'agisse du roi avec ses sujets ou du maître avec ses esclaves ${ }^{\text {Io }}$. Enfin, il marquait un intérêt prononcé pour l'ethnographie : on trouvait dans son œuvre des développements sur les coutumes des Celtes (Posidonios est à l'origine des développements ethnographiques sur les Celtes que l'on trouve chez Diodore, Strabon et César), des Germains, des Juifs et des Parthes ${ }^{\text {II }}$.

Parmi les fragments de Posidonios, quatre concernent les Parthes et les guerres entre Parthes et Séleucides. Deux sont d'ordre ethnographique: Strabon cite un passage de Posidonios expliquant le fonctionnement du Sénat des Parthes (Strabon I I, 9, 3 = E-K F. 282) et Athénée deux passages décrivant les banquets des rois parthes, passages qu'il attribue pour l'un au livre 5, pour l'autre au livre 16 des Histoires (Athénée I 52 f-I 53 b = E-K F. 57 et F. 64). Ce second passage (F. 64), d'après Athénée, était inséré dans le récit de l'expédition de Démétrios et de sa captivité ${ }^{12}$ : le livre 16 contenait donc l'histoire de l'expédition malheureuse de Démétrios II.

Les troisième et quatrième fragments (Athénée $439 \mathrm{e}=\mathrm{E}-\mathrm{K} \mathrm{F} .63$ et Athénée 466 b-c $=E-K$ F. 65) sont d'ordre historique. Ils proviennent également du livre $\mathrm{I} 6$ et ont trait à l'expédition d'Antiochos VII ${ }^{13}$ et à ses conséquences en Babylonie ${ }^{14}$. 266-267

9. Voir par ex. E-K F. 58 ; F. 59 ; F. 61a-b; F. 63, F. 65 ... Sur les anciens Romains : F. 265-

10. Voir E-K F. 57 ; F. 59 ; F. 60; F. 253 (long fragment sur le tyran athénien Athénion).

I I. Sur les Celtes : E-K F. 67 ; F. 68; F. 68; 272; F. 274. Sur les Germains : F. 73 et F. 277b; sur les Juifs, F. 278 ; sur les Parthes, F. 57 ;F. 64 ; F. 282.

I 2. Voir Athénée I 53 b: «Dans le livre 16 , au cours du récit sur le roi Séleucos dans lequel il raconte qu'après être monté en Médie et avoir fait la guerre à Arsacès il fut fait prisonnier par le barbare et passa un long moment chez Arsacès traité en roi, (Posidonios) écrit... ". La mention du roi Séleucos est ici une erreur, aucun Séleucos n'ayant été fait prisonnier par les Parthes. Il s'agit en fait de Démétrios II.

13. Athénée 439 e =E-K F. 63 : Athénée cite les paroles qu'aurait prononcées Phraate II au moment d'enterrer Antiochos VII et présente ce dernier comme "celui qui a fait la guerre à Arsacès en Médie, ainsi que le rapporte Posidonios dans le livre 16 des Histoires ».

14. Le dernier fragment (Athénée $466 \mathrm{~b}-\mathrm{c}=\mathrm{E}-\mathrm{K}$ F. 65) évoque Himéros, le cruel gouverneur que Phrate II mit à la tête de la Babylonie après la mort d'Antiochos VII. 
Si le livre I6 des Histoires racontait l'expédition de Démétrios II, sa captivité, l'expédition d'Antiochos VII et les lendemains de la guerre, il est probable qu'on trouvait au livre 5 un premier récit de l'expédition de Démétrios II Is. Les Histoires commencent en effet en 146 et les fragments indiquent que dès le livre III Posidonios s'occupait d'histoire syrienne, plus précisément de la guerre civile qui éclate en I4s entre Démétrios II et son rival Diodote Tryphon ${ }^{16}$. On sait par ailleurs qu'au livre I4 il évoquait le règne d'Antiochos VII ${ }^{17}$, qui succéda à son frère Démétrios en ${ }^{1} 38$ lorsque ce dernier eut été fait prisonnier par les Parthes : c'est donc qu'au livre 14, l'histoire du premier règne de Démétrios ${ }^{18}$ et de son expédition malheureuse était terminée. Or, au livre 5 , Posidonios, comme l'indique un des fragments d'Athénée que nous avons mentionné plus haut, décrit une première fois les banquets des Arsacides; cette description devait être motivée par un événement particulier : il s'agissait, vraisemblablement, de l'expédition de Démétrios II. Au moment de raconter cette expédition, Posidonios se livrait à un excursus sur les Parthes tout à fait conforme à son goût pour l'ethnographie. La façon dont Athénée introduit le fragment du livres sur les banquets des rois parthes renforce d'ailleurs l'hypothèse selon laquelle cette description faisait partie d'une digression sur les Parthes: «au livre 5", écrit-il, «dans son récit sur les Parthes, Posidonios dit que...» (દ่v $\delta \dot{\varepsilon} \tau \hat{n}$

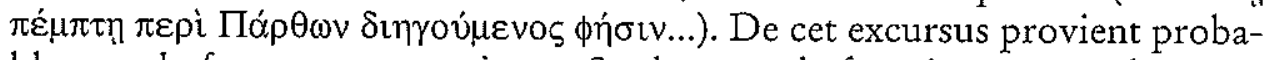
blement le fragment transmis par Strabon sur le fonctionnement du Sénat des Parthes (Strabon I I, 9, 3 = E-K F. 282).

On trouvait donc au livre 5 des Histoires un premier récit de l'expédition de Démétrios accompagné d'un excursus sur les Parthes comportant au

I5. Voir sur ce point F. JACOBY, FGrH II'2, Kommentar p. I64-I65.

I6. Voir F. JACOBY, FGrH II", Kommentar p. I64 ; I.G. KIDD, Posidonius II, op. cit. (n. 6), p. 284-286. Un fragment tiré du livre III (Athénée $4,176 \mathrm{~b}-\mathrm{c}=\mathrm{E}-\mathrm{K}$ F. 54 ) évoque une guerre entre Apaméens et habitants de la cité de Larissa dont le contexte est très vraisemblablement la guerre entre Tryphon et Démétrios : les cités prenaient en effet parti pour l'un ou l'autre et pouvaient se retrouver en guerre l'une contre l'autre. Diodore raconte ainsi une guerre entre Arados et Marathos $(33,4)$.

17. Voir Athénée I 2, 540b-c = E-K F. 6 ra : fragment portant sur les réceptions somptueuses qu'organisait Antiochos VII.

i 8. On parle du premier règne de Démétrios car celui-ci, ayant réussi à s'échapper de sa prison parthe lors de l'expédition de son frère, remonta sur le trône de Syrie en 129 ; il y resta jusqu'en 126 . 
moins un volet ethnographique; l'historien reprenait ensuite ce récit ainsi que celui de la captivité de Démétrios au livre I6, avant de raconter la guerre d'Antiochos VII contre les Parthes.

Les fragments ne sont pas le seul moyen de connaître le contenu des Histoires. Diodore de Sicile en effet, dans les livres 33-34 de la Bibliothèque Historique, traite des guerres de Démétrios II et d'Antiochos VII. Or, on considère en général que l'œuvre de Posidonios constitue la source de Diodore de Sicile à partir du livre 32 ou 33 de la Bibliothèque Historique, au moment où s'arrête le récit de Polybe que l'historien suivait jusque-là ${ }^{19}$. Certes, à partir du livre 20, la Bibliothèque Historique ne nous est parvenue que sous forme de fragments transmis par Photius et les excerpteurs byzantins. La comparaison entre les fragments de Posidonios et ceux des derniers livres de Diodore rend cependant indubitable le fait que le second, dans cette partie de son œuvre, utilisa le premier comme source principale de son récit ${ }^{20}$.

Parmi les fragments tirés des livres 33 et 34 de la Bibliotbèque Historique, plusieurs concernent les Parthes et les guerres entre Parthes et Séleucides. Le premier (Diodore de Sicile 33, I8) est un portrait élogieux du grand roi parthe Mithridate I qui provient probablement de l'excursus sur les Parthes par lequel Posidonios faisait précéder son récit de l'expédition de Démétrios : outre un volet ethnographique, cet excursus devait comprendre un volet historique. Les fragments suivants concernent l'expédition d'Antiochos VII et s'achèvent avec la mention du cruel gouverneur que le roi parthe installe à Babylone après la fin de la guerre ${ }^{21}$.

19. Voir SCHWARTZ, RE col. 690-691 (1905); F. JACOBY, FGrH 87, Kommentar p. I 57 -159 (1926); P. A. BRUNT, "On historical fragments and epitomes ", CQ 30, 1980, p. 477-494, ici p. $48 \mathrm{I}$; K.S. SACKS, Diodorus Siculus and the first Century, Princeton, 1990.

20. On sait que Diodore connaissait l'œuvre de Posidonios puisqu'il l'utilise au livre V de la Bibliothèque Historique, pour sa description des Celtes (voir sur ce point A. Momigliano, Sagesses barbares, Paris, 1979, p. 80-85) et en dernier lieu, I.G. KIDD, Posidonius II, op. cit. [n. 6], p. 307-315). Le parallèle le plus célèbre entre les fragments de Posidonios et de Diodore est constitué par le récit de la longue révolte d'esclaves qui secoua la Sicile entre 136 et I 32 av. J.-C. : comparer la description de Damophile, le riche propriétaire à cause de l'arrogance duquel éclata la révolte, chez Posidonios (Athénée I 2, 542b $=\mathrm{E}-\mathrm{K}$ F. 59) et chez Diodore $(34,2,34)$. On peut également rapprocher les récits de l'ambassade de Scipion l'Africain chez Ptolémée Physcon, en I40I 39 : voir pour Posidonios Athénée 12, 549d-e =E-K F. 58 et Athénée 6, 273a = E-K F. 265 et pour Diodore 33, 28b.

2I. Sur Antiochos VII, voir Diodore de Sicile $34 / 35$, ch. Is à ig; sur Himéros (appelé Euhéméros par Diodore), ch. 21 . 
On ne peut certes prétendre avoir accès, par ces fragments, au texte même de Posidonios : les études sur Diodore ont montré que, contrairement à ce qu'on a affirmé pendant longtemps, l'historien ne se contentait pas de coller bout à bout les passages qu'il empruntait à ses prédécesseurs mais qu'il les réécrivait et les unifiait en leur imposant non seulement son style mais aussi ses propres conceptions historiques ${ }^{22}$. N'oublions pas qu'en outre Diodore a considérablement réduit le matériau dont il s'est inspiré : les 52 livres de Posidonios se trouvent ainsi résumés par lui en $8 / 9$ livres ! On imagine les déformations auxquelles peut aboutir une réduction aussi drastique $^{23}$. Il paraît peu douteux cependant que l'on peut prétendre savoir, grâce à lui, quels sujets étaient abordés par Posidonios et comment il les traitait (jugement positif ou négatif, par exemple). Le texte de Diodore est d'autant plus précieux que cet historien, nous le savons, ne mélange pas ses sources : il choisit, pour une période donnée, un historien et résume son récit sans le contaminer avec ceux d'autres auteurs. Nous sommes donc autorisés à considérer qu'à travers les fragments des livres 33-34 de Diodore de Sicile, nous retrouvons un témoin du récit posidonien sur les guerres entre Parthes et Séleucides, bien plus proche de sa source que ne peuvent l'être les Histoires Philippiques, compilées tardivement.

Le « corpus posidonien », pour les livres des Histoires qui nous intéressent, se compose donc des fragments directs de Posidonios ainsi que des fragments des livres 33-34 de la Bibliothèque Historique de Diodore. C'est

22. Sur le travail d'historien de Diodore, voir K.S. SACKS, op. cit. (n. 19), ainsi que l'introduction générale de F. CHAMoux dans l'édition Budé du livre I de la Bibliothèque Historique, Paris, 1993, notamment p. XV-XXII. L'idée que Diodore ne fait qu'un travail de compilateur a été exprimée en termes très sévères par SCHWARTZ, $R E$ col. 663 . Les travaux de J. PALM, UUber Sprache und Stil des D. von Sizilien, Lund, I 955 , fondés sur la comparaison entre le livre III de Diodore et les fragments d'Agatharchide de Cnide, ont montré au contraire que Diodore avait réécrit tous les passages qu'il citait afin d'obtenir une réelle unité stylistique. Du point de vue des conceptions historiques, une profonde unité apparaît également. On peut prendre pour exemple la description du bon ou du mauvais chef d'État : elle est la même d'un bout à l'autre de la Bibliothèque Historique et on doit admettre qu'elle correspond bien à une vision diodoréenne; voir sur ce point l'analyse de K. SACKS, op. cit. (n. 19), ch. 2 et 3, qui s'attache notamment (p. 42-44) à l'étude du terme récur-

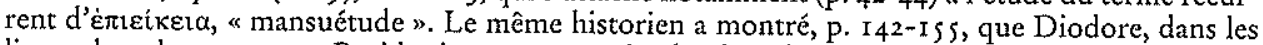
livres dont la source est Posidonios, se montrait plus hostile aux Romains que sa source et lui faisait donc subir une réelle déformation.

23. C'est la raison pour laquelle il nous semble excessif d'inclure des passages de Diodore dans une collection de fragments de Posidonios, comme l'a fait $G$. Theiler. 
à ce corpus que nous comparerons les autres récits qui nous sont parvenus sur les guerres entre Parthes et Séleucides, et notamment celui de Trogue/Justin, le plus long, afin d'établir ce qui, dans ces récits, peut être considéré comme proprement posidonien.

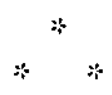

Présentons d'abord rapidement les passages qui dans l'œuvre de Trogue/Justin se rapportent aux guerres entre Parthes et Séleucides. Trogue/Justin évoque ces guerres aux livres 36 et 38 des Histoires Philippiques: il raconte la campagne de Démétrios et sa capture au début du livre $36(36, \mathrm{I}, 2-5)$ puis reprend ce récit au livre 38 , juste avant de raconter la guerre d'Antiochos VII ( $38,9-10)$. L'adoption de cette structure éclatée renforce la thèse selon laquelle il utilise Posidonios à cet endroit de son œuvre : j'ai dit plus haut, en effet, que Posidonios dans les Histoires racontait deux fois l'expédition de Démétrios, une première fois au livre 5 , une seconde fois au livre 16 , juste avant de faire le récit de l'expédition de son frère Antiochos VII ${ }^{24}$. 'Trogue reprend ce mode d'organisation du récit.

Trogue par ailleurs, comme Posidonios, faisait vraisemblablement précéder son récit de la campagne de Démétrios par un excursus sur les Parthes dans lequel il rappelait l'histoire de ce peuple. Ce récit n'apparaît pas dans l'abrégé qu'a donné Justin des Histoires Philippiques mais on en trouve des traces dans les Prologues - ces courts résumés de chacun des 40 livres de Trogue qui ont été rédigés alors que l'œuvre circulait encore sous sa forme complète et qui permettent à la fois de savoir ce qu'elle contenait et de mesurer l'ampleur des coupes opérées par l'abréviateur. Le prologue du livre 35 indique en effet que Trogue à la fin de ce livre, juste avant de raconter la campagne de Démétrios II, faisait un retour sur l'histoire des Parthes : «à partir de là », lit-on dans le prologue - c'est-à-dire en I44, au moment où l'usurpateur Tryphon chasse Démétrios de Syrie - « on remonte aux troubles de la Haute-Asie causés par Aréthée et Arsace le Parthe» (repetit inde superioris Asiae motus factos per Araetheum et Arsacen

24. On ne retrouve cette structure «éclatée » caractéristique des récits de Posidonios et Trogue ni chez Flavius Josèphe ni chez Appien, qui tous deux racontent d'une traite l'expédition de Démétrios, sa captivité puis la campagne d'Antiochos VII. 
Parthum) 25 . Le verbe "repetere" annonce un de ces nombreux retours en arrière auxquels se livre Trogue dans les Histoires Philippiques au sujet de l'origine ou de l'histoire de tel ou tel des peuples qu'il évoque ${ }^{26}:$ pour que le lecteur comprenne la situation dans laquelle se trouvaient les Parthes au moment où Démétrios engagea contre eux une guerre de reconquête, Trogue, comme Posidonios et comme Diodore, se livre à une digression sur ce peuple ${ }^{27}$.

La forme adoptée par Trogue/Justin pour son récit des guerres du second siècle entre Parthes et Séleucides confirme donc la dépendance des Histoires Philippiques par rapport à l'œuvre de Posidonios.

Nous pouvons maintenant passer à l'analyse des textes portant sur les guerres que les Séleucides menèrent contre les Parthes au II ${ }^{e}$ siècle. Ces textes se concentrent sur trois épisodes principaux: la campagne de Démétrios; ses années de captivité chez les Parthes; la campagne d'Antiochos VII. C'est avec le premier de ces épisodes que nous allons commencer notre étude ; c'est aussi celui qui recevra l'analyse la plus longue.

\section{La campagne de Démétrios II (I40-I39 av. J.C.)}

Nous ne disposons sur la campagne de Démétrios d'aucun fragment de Posidonios ni de Diodore. Les sources sont constituées par un passage de I Macc. (I Macc. I 4, I-3) ainsi que par des textes de Trogue $(36, \mathrm{I}, 2-5)$ et de Flavius Josèphe $(A J$ I3, I $84-186)$. Le déroulement des événements semble

25. L'identité de cet «Aréthée » reste mystérieuse. Selon B. VAN WICKEVOORT CROMMELIN, "Die Parther und die parthische Geschichte bei Pompeius Trogus-Iustin ", dans J. WIESEHÖFER, Die Partherreich und seine Zengnisse, Stuttgart, 1998, p. 259-277, ici p. 265, il s'agirait d'un satrape séleucide rebelle, inconnu par ailleurs; son nom pourrait indiquer qu'il était arménien (le nom "Aretaios » appartient à l'onomastique arménienne).

26. Sur ce point voir Paul JAL, « $\AA$ propos des Histoires Philippiques de Trogue Pompée: quelques remarques ", REL 65, 1987, p. 194-209.

27. Pas plus que pour Posidonios - dont on sait seulement, grâce à Diodore, que son excursus évoquait le roi Mithridate I - on ne sait jusqu'à quelle date Trogue remontait : "Arsacès " est un nom générique qui peut désigner n'importe lequel des rois parthes. Selon B. vaN WICKEVOORT CROMMELIN, art. cit. (n. 25), Arsaces désignerait Mithridate I : on sait en effet grâce au Prologue du livre 30 que Trogue dans ce livre racontait l'Anabase d'Antiochos III, vaste expédition par laquelle le roi tenta de rétablir son autorité sur la Parthyène et les autres satrapies orientales (2 I 2204 av. J.-C.) ; il est plausible que Trogue ait profité de cette occasion pour faire le récit des débuts des Parthes; au livre 35, dans ce cas, il n'aurait qu'à raconter les conquêtes récentes de Mithridate I. 
cependant assuré dans ses grandes lignes. D'après Trogue et Josèphe, Démétrios reçut dans son expédition l'appui d'un grand nombre des peuples récemment soumis aux Arsacides : selon Josèphe, il lança même son expédition à la demande d'habitants de Mésopotamie ( $A J$ I 3, I 84 ). Le début de l'expédition est donc victorieux : Démétrios fut « reçu avec empressement par les gens du pays ", selon Josèphe, et Trogue explique, plus précisément, qu'il remporta plusieurs succès contre l'armée de Mithridate I. Il subit cependant par la suite, dans des circonstances qu'aucun des deux auteurs ne détaille, un grave échec militaire et se fit capturer par le roi des Parthes, après avoir été " trompé par une paix simulée ", selon Trogue (36, I, 5). I Macc. est très bref sur le déroulement de la guerre mais mentionne également la capture de Démétrios par Arsacès ${ }^{28}$.

Deux différences importantes apparaissent cependant entre les récits de Trogue/Justin et de Josèphe. La première porte sur les motifs pour lesquels Démétrios engagea la campagne. Selon Trogue/Justin, Démétrios, une fois qu'il eut triomphé de son rival Alexandre Balas et se fut établi sur le trône de ses ancêtres, "se livra aux passions de la jeunesse et s'abandonna à la mollesse » (vitiis adulescentiae in segnitiam labitur). Il ne tarda pas, par conséquent, à se faire mépriser par tous (contemptum apud omnes... contraxit). Il décida alors, comme de tous côtés les villes se détachaient de son empire, d'aller faire la guerre aux Parthes, pour «effacer la honte de sa nonchalance " (cum ab imperio ejus passim civitates deficerent, ad abolendam segnitiae maculam, bellum Parthis inferre statuit).

Trogue/Justin reste très imprécis dans ce passage sur le contexte dans lequel Démétrios lança son expédition; il ne donne aucune information sur l'identité de ces «villes» qui se détachaient de l'empire et privilégie, pour expliquer la décision de Démétrios, une interprétation de type psychologisante et moralisante: Démétrios avait suscité tellement de mépris qu'il décida de lancer une guerre contre les Parthes afin de regagner du prestige auprès de ses sujets. L'expédition du roi n'obéit à aucun autre motif que celui-là, et le fait qu'elle soit dirigée spécifiquement contre les Parthes semble ressortir du plus pur hasard.

28. Voir I Macc. I4, 2-3: "Arsace, roi de Perse et de Médie, ayant appris que Démétrios était entré sur son territoire, envoya un de ses généraux le capturer vivant. Celui-ci partit et défit l'armée de Démétrios, dont il se saisit. Il l'amena à Arsace, qui le mit en prison. " 
Flavius Josèphe au contraire inscrit l'expédition de Démétrios II dans un contexte historique précis et lui donne deux justifications : volonté de récupérer la totalité des possessions des Séleucides (rappelons qu'en I4I, Mithridate I, roi des Parthes, se rend maître de la Babylonie), et lutte contre Tryphon, usurpateur qui dès l'accession de Démétrios au trône de Syrie en I 45 lui disputa le pouvoir. Démétrios, explique ainsi Josèphe, « passa en Mésopotamie, souhaitant s'en emparer ainsi que de Babylone, afin, une fois qu'il se serait rendu maître des satrapies supérieures, de faire de ces régions le point de départ à partir duquel il récupérerait tout le reste de son royaume. En effet, les Grecs et les Macédoniens qui vivaient là-bas lui envoyaient sans arrêt des ambassades en lui promettant, s'il venait chez eux, de le rejoindre pour faire ensemble la guerre à Arsacès. Exalté par ces espérances, il s'élança chez eux, bien décidé, s'il soumettait les Parthes et réunissait une armée suffisnate, à combattre Tryphon et à le chasser de Syrie » 29.

On le voit, il n'est en rien question de la mollesse de Démétrios dans ce passage ; il lance son expédition parce qu'il se trouve face à de réels impératifs historiques (reconquête de territoires, reconquête de son trône) et que les Grecs et Macédoniens de Mésopotamie lui promettent leur aide. I Macc. mentionne également la volonté de lutter contre Tryphon pour expliquer le départ de Démétrios - c'est même pour lui la seule raison ${ }^{30}$.

La seconde grande différence entre les historiens porte sur l'identité de ces peuples qui aidèrent Démétrios dans son entreprise - qui le poussèrent même, d'après Flavius Josèphe, à passer l'Euphrate. Trogue évoque les "peuples de l'Orient » (Orientis populi), «Perses, Élyméens, Bactriens », et explique qu'ils se seraient ralliés à Démétrios "avec plaisir» (non inviti) «parce qu'ils détestaient la cruauté d'Arsacide, roi des Parthes, et parce que, habitués dès longtemps au joug des Macédoniens, ils supportaient avec peine l'arrogance de leurs nouveaux maitres » (et propter Arsacidae, regis Parthorum, crudelitatem et quod, veteri Macedonum imperio adsueti, novi populi superbiam indigne ferebant) ${ }^{3 x}$.

Flavius Josèphe, lui, évoque « les Grecs et les Macédoniens qui habi-

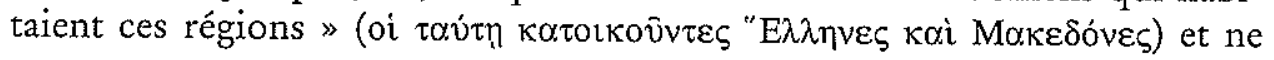

29. $A J \mathrm{I}_{3}, \mathrm{I} 84$.

30. I Macc. I 4, I-3: « en l'année 172 , le roi Démétrios réunit son armée et s'en alla en Médie se procurer des secours afin de combattre Tryphon ».

3I. Trogue Pompée 36, I, 3 . 
donne pas les motifs de leur attitude envers Démétrios : on suppose qu'ils préfèrent vivre sous une domination gréco-macédonienne que sous une domination étrangère.

Peut-on savoir laquelle des deux versions est la plus proche du récit de Posidonios?

Commençons par examiner le premier point, relatif aux motifs de Démétrios II. Il nous faut pour cela faire un détour par la réalité historique ${ }^{32}$. Démétrios II, en I45, monte sur le trône de Syrie. À peine installé, il rencontre l'opposition d'un usurpateur, Diodote Tryphon, qui en I 44 le chasse d'Antioche et en $\mathrm{I}_{42}$-I 4 I se proclame roi. Démétrios cependant a conservé l'autorité sur toute une partie de l'empire séleucide ${ }^{33}$, dont la Mésopotamie et la Babylonie: un fragment de Diodore de Sicile indique ainsi que Tryphon, une fois qu'il se fut proclamé roi, entreprit une guerre contre "les satrapes et les stratèges du roi légitime 》 ( $\tau \hat{\omega} v \sigma \alpha \tau \rho \alpha \pi \hat{\omega} v \kappa \alpha i \tau \hat{\mathrm{\omega}} \mathrm{v}$

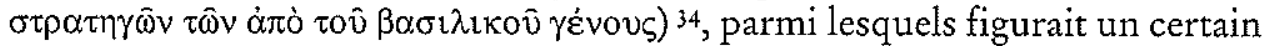

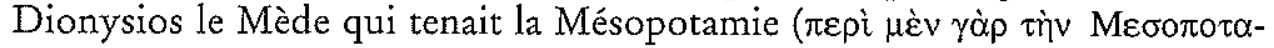

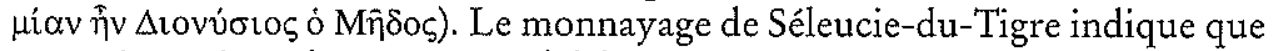
cette cité était également restée fidèle à Démétrios II 35 .

Or, Séleucie et la Babylonie, en I4I, tombent aux mains de Mithridate I. Il est donc bien évident que, lorsque Démétrios lance son expédition parthique en $\mathrm{I}_{4} \mathrm{O}$, c'est certes parce qu'il cherche à reconquérir les territoires nouvellement conquis par Mithridate, mais également parce qu'il a besoin de récupérer des alliés mésopotamiens dans le cadre de sa lutte contre l'usurpateur.

Le récit de Flavius Josèphe, qui évoque à la fois la volonté de reconquête de tout son territoire par Démétrios et le rôle que joua dans cette reconquête la lutte contre Tryphon semble donc le plus proche de la réalité historique. Les Histoires Philippiques, qui passent totalement sous silence,

32. Voir l'exposé des événements dans Éd. Will, $H P M H^{2}$, I982, p. 404-410.

33. Flavius Josèphe indique qu'il tenait la Cilicie $\left(A J\right.$ I $\left.3, I_{4} 5\right)$, et on le voit pendant toute cette période aux prises avec les Juifs (outre Flavius, $A J$ r 3, I48-184, voir $I$. Macc. 12, 24 ; $13,34-40$ ).

34. DS $33,28$.

35. Voir G. LE RIDER, Suse sous les Séleucides et les Parthes. Les trouvailles monétaires et l'bistoire de la ville, Paris, 1965, p. 364-367 et p. 369: le monnayage de Mithridate I succède à celui de Démétrios II. 
à ce stade du récit, les démêlés de Démétrios avec Tryphon ainsi que les changements occasionnés en Orient par l'expansion parthe, se privent au contraire des facteurs permettant de comprendre la décision de Démétrios II en I40. Le motif qu'elles assignent à l'expédition de Démétrios (« effacer la honte de sa nonchalance ») implique en outre que celui-ci régnait de plein droit lorsqu'il déclara la guerre aux Parthes, ce qui est faux. La version des événements que propose Trogue/Justin paraît donc ici très déformée par rapport à la réalité historique.

Comment savoir maintenant lequel des detux récits est le plus proche, non de la réalité historique, mais du récit de Posidonios?

Pour ce qui concerne la prise en compte du facteur parthe dans la décision de Démétrios, nous pouvons déjà proposer une réponse : nous avons vu que Posidonios faisait précéder son récit de l'expédition du Séleucide d'un excursus sur les Parthes et racontait le règne de leur roi Mithridate I. Il exposait donc les conditions créées en Orient par les conquêtes des Arsacides. C'est par conséquent Flavius Josèphe qui est ici le plus proche du texte de Posidonios.

Pour ce qui concerne le rôle de Tryphon, ce sont les fragments de Diodore qui peuvent nous renseigner. Certes, aucun de ces fragments ne concernent l'expédition de Démétrios elle-même. Un certain nombre d'entre eux en revanche traite de la lutte entre Tryphon et Démétrios II (voir $33,4 a ; 33,28 ; 33,28 a)$ : visiblement, l'historien consacrait à ce sujet un nombre de pages relativement élevé et il était conscient de son importance. C'est par ailleurs grâce à l'un de ces fragments que nous savons que Démétrios II, bien que chassé par Tryphon, avait gardé des alliés en Mésopotamie : Diodore établissait donc un lien entre la rivalité pour le trône syrien et l'expédition parthique de Démétrios II. Les fragments de Diodore étant des témoins de l'œuvre de Posidonios, on doit conclure que la version des événements proposée par Flavius Josèphe est encore une fois la plus proche de celle de Posidonios. Prise en compte des conditions créées par la conquête parthe, récit de la rivalité entre Tryphon et Démétrios: les deux motifs expliquant la décision de Démétrios étaient bien présents chez Posidonios. On les retrouve, très rapidement évoqués, chez Flavius Josèphe; ils ont disparu des Histoires Philippiques.

Cependant, il n'en était pas ainsi dans la version non abrégée de l'œuvre de Trogue. Le prologue du livre 35 des Histoires Philippiques nous apprend en effet que l'histoire des démêlés entre Tryphon et Démétrios était abon- 
damment évoquée par Trogue avant le récit de l'expédition de Démétrios, et nous avons vu plus haut que ce livre contenait également une digression sur les Parthes ${ }^{36}$. Chez Trogue comme chez Diodore étaient donc développés les deux thèmes permettant de placer la guerre de Démétrios dans son contexte historique tels qu'on les trouvait chez Posidonios. De ces thèmes, on ne trouve quasiment aucune trace dans la version abrégée des Histoires Philippiques: Justin n'a d'ailleurs conservé du livre 35 que deux courts chapitres. Il n'omet pas totalement, il est vrai, le personnage de Tryphon, mais il ne l'évoque qu'après le récit de la campagne de Démétrios ${ }^{37}$, ce qui supprime toute connection entre son usurpation et l'expédition parthique du roi.

On doit en conclure que Justin a volontairement escamoté, dans son résumé des Histoires Philippiques, les deux grands facteurs qui permettaient de comprendre pourquoi Démétrios II passa chez les Parthes en I40. Il leur a préféré une explication unique de type moralisant : le roi, mou et indolent, aurait lancé son expédition pour effacer le mépris qu'il suscitait auprès de ses sujets. Cette explication ne pouvant logiquement apparaitre chez Trogue - selon lequel le roi n'était plus sur le trône à cette date - il faut admettre que c'est Justin lui-même qui l'a inventée ${ }^{38}$. Elle est d'autant plus étonnante que l'image de Démétrios II telle qu'elle apparaît chez Diodore et chez Flavius Josèphe n'est pas tant celle d'un roi mou que d'un roi cruel : un long fragment de la Bibliothèque Historique détaille les multiples crimes dont il se serait rendu coupable auprès de ses sujets, suscitant la révolte des habitants d'Antioche et la haine de tous les Syriens 39 ; Flavius Josèphe de même

36. Voir la fin du Prologue du livre 35: Trogue raconte a comment la guerre éclata entre Démétrios et Diodote Tryphon et comment Démétrios fut chassé par Tryphon du royaume de Syrie. De là, on remonte aux troubles de la haute Asie causés par Aréthée et Arsacès le Parthe ». 37. Trogue/Justin 36, 1, 7-8.

38. L'intervention de Justin est confirmée par le fait que, comme le montre l'étude de J.C. Yardley, on trouve dans ce passage du livre 36 plusieurs tournures propres à l'époque où les Histoires Philippiques ont été résumées : l'expression "abolendam... maculam " trouve ainsi un parallèle chez Fronton - on la retrouve ensuite chez Ammien Marcellin ; l'expression « trompé par une paix simulée" (pacis simulatione deceptus) évoque un passage de Quintilien. Sur ce passage, voir J.C. YARDLEY, Justin and Pompeius Trogus. A study of the language of Justin's Epitome of Trogus (Phoenix 41), Toronto, 2003, p. I71. Des tournures vagues du type " comme de tous côtés les villes se détachaient de son empire » sont en outre révélatrices d'un résumé : voir L. SANTIAMANTINI, Fonti e valore storico di Pompeo Trogo (Iustin. 35 e 36), Gênes, 1972, p. 56.

39. $\operatorname{DS}_{33,4}$ 


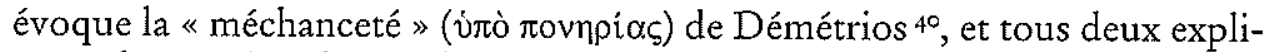
quent l'ascension de Tryphon par la cruauté du roi légitime : ayant compris que Démétrios était détesté, Diodote se serait facilement rallié des partisans dans le royaume ${ }^{4 \mathrm{I}}$. Certes, l'image d'un être indolent et livré à ses plaisirs n'est pas totalement absente du récit de Diodore: dans un fragment on lit que, pendant un séjour à Laodicée, Démétrios «passa son temps dans la nonchalance ( $\dot{\alpha} \alpha \theta \dot{u} \mu \omega s)$ ), donnant des banquets et se livrant sans retenue

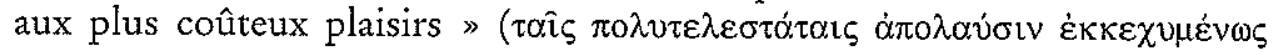
$\chi \rho(\dot{\mu} \mu \varepsilon \vee)^{42}{ }^{42}$.

Il reste que le trait dominant de Démétrios II, chez Diodore, est bien davantage la cruauté envers ses sujets que l'abandon aux plaisirs. Or, Justin nie totalement cet aspect cruel du personnage : si Démétrios I, indique-t-il, était plein de superbia et suscitait la haine chez ses sujets, Démétrios II, lui, est un roi mou ne suscitant que le mépris - pendant son premier règne en tout cas ${ }^{43}$. L'image que propose Justin du roi est donc en contradiction avec celle de Posidonios et Diodore, et très probablement avec celle qu'en donnait Trogue lui-même. Au risque d'utiliser un argument e silentio, j'ajouterais que l'explication qu'il avance pour rendre compte de l'attitude de Démétrios II (faire une guerre pour effacer le mépris de ses sujets) ne se trouve jamais employée, à ma connaissance, dans d'autres passages des Histoires Philippiques, ni chez Diodore: dans l'une et l'autre cuvre, on voit les rois faire la guerre pour occuper leurs sujets, par appât du gain, par ambition, mais jamais pour « effacer la honte de leur nonchalance».

La question qui se pose face à cette intervention de Justin est évidente : pourquoi ? Pourquoi l'abréviateur a-t-il modifié l'image de Démétrios II et a-t-il passé sous silence les rivalités entre Démétrios et Tryphon ? On peut proposer pour cette question différentes réponses. Invoquons d'abord l'exigence rhétorique. Il est très clair que Justin dans toutes les Histoires Philippiques recherche davantage l'effet rhétorique que l'exactitude historique ${ }^{44}$;

40. Flavius Josèphe, $A J$ I $3,120$.

4I. DS 33,4 ; ; Flavius Josèphe, $A J$ i3, 135 .

42. DS 33,9 .

43. Voir Trogue/Justin 3, I, I : « Il se rendit par son indolence aussi méprisable aux yeux de ses peuples que son père s'était rendu odieux par son orgueil. "Voir aussi 36, 1, 9. Après son retour de captivité cependant, Démétrios II à son tour fait preuve de superbia (voir $39, \mathrm{I}, 3$ ).

44. Selon J.C. Yardley, qui établit de très nombreux parallèles entre la langue de Justin et celle de Quintilien, Justin aurait même été professeur de rhétorique. 
la variété étant une des exigences de l'art rhétorique, on conçoit qu'il ait tenté de marquer un contraste fort entre Démétrios $I$, roi plein de superbia, et son sucesseur, adonné à la mollesse - le troisième de la lignée, Antiochos VII, parvenant à éviter l'un et l'autre défaut ${ }^{45}$. L'effet de variété entre Séleucides est ainsi garanti et l'attention du lecteur ne faiblit pas. Insister sur l'indolence de Démétrios donne en outre à son expédition au-delà de l'Euphrate une raison simple, permettant de laisser de côté un long développement probablement jugé fastidieux sur les débuts des Parthes en Asie ainsi que sur les démêlés entre Tryphon et Démétrios, dont la chronologie complexe aurait pu ennuyer le lecteur romain. Enfin, cette explication est conforme à l'intention moralisante de Justin, très présente tout au long du résumé des Histoires Philippiques. Tendance moralisante, goût pour les contrastes, volonté de simplifier un récit complexe, ces trois facteurs peuvent expliquer l'intervention de Justin au livre 36 .

Je pense pourtant qu'une autre explication est possible - qui n'exclut pas les précédentes mais vient s'y ajouter. Pour la comprendre, il nous faut nous pencher maintenant sur les récits du déroulement de l'expédition de Démétrios elle-même.

J'ai indiqué plus haut que les versions de Trogue/Justin et de Flavius Josèphe différaient également sur l'identité des peuples soumis aux Parthes qui l'aidèrent dans son expédition et lui permirent de remporter ses premiers succès : «Perses, Élyméens, Bactriens » chez Trogue, «Grecs et Macédoniens » chez Flavius Josèphe. Les premiers sont censés agir à cause de la cruauté du roi des Parthes et parce qu'ils ne supportent pas la superbia de ce peuple, les motifs des seconds ne sont pas expliqués mais semblent ressortir d'une sorte de solidarité « ethnique » entre Gréco-Macédoniens.

Il est probable que les Grecs fraîchement passés sous domination parthe, ou en tout cas une partie d'entre eux, firent appel à Démétrios comme l'affirme Flavius Josèphe. On sait que Mithridate I se disait «philhellène » et à aucun moment de l'histoire de l'empire parthe on n'entend parler d'une révolte des Grecs de cet empire. Ils venaient cependant à peine de passer sous domination parthe lorsque Démétrios franchit l'Euphrate en I40, et un fragment de Diodore de Sicile indique que dix ans plus tard, lorsque Antiochos VII mena sa guerre contre les Parthes, il reçut le soutien 
de la cité de Séleucie-du-Tigre ${ }^{6}$ : il paraît donc fort probable qu'en I40, de la même façon, une partie des Grecs de Mésopotamie furent favorables à Démétrios - la situation pouvant différer d'une cité à l'autre. De la même façon, plus d'un siècle après, bon nombre des cités grecques de Mésopotamie se donnèrent volontairement à Crassus lorsqu'il franchit une première fois l'Euphrate en $54^{47}$.

Par ailleurs, il n'est pas douteux non plus que, comme le dit Trogue/ Justin, Démétrios reçut dans sa campagne le soutien des Perses et des Élyméens. On sait en effet que, avant même la conquête parthe, en Iran et en Mésopotamie, des dynastes locaux avaient pris leur autonomie par rapport à la tutelle séleucide ${ }^{48}$. C'est le cas de la Perside, dont l'indépendance est attestée par le monnayage d'une dynastie indigène, mais également de l'Élymaïde, région de Susiane qui prend son indépendance dans les années 140 sous la houlette d'un certain Kamniskirès, connu lui aussi par les monnaies qu'il a émises ${ }^{49}$. Il paraît logique que ces dynastes, dont l'irruption parthe remettait l'autonomie en cause, se soient alliés à Démétrios pour protéger leur indépendance. La version que Justin présente des événements semble donc elle aussi plausible du point de vue historique - à condition d'exclure de la liste des peuples ayant soutenu Démétrios les Bactriens, bien éloignés du champ des opérations militaires et dont la présence dans le texte s'explique probablement par l'imprécision des connaissances géographiques de l'auteur, qu'il s'agisse de Trogue ou de Justin! Les versions de Trogue et de Flavius Josèphe n'entrent pas en contradiction l'une avec l'autre, et aucun indice ne permet de savoir si Posidonios pour sa part évoquait le ralliement des Grecs ou des dynastes orientaux ; peut-être mentionnait-il les deux.

46. DS 34, I9: le roi parthe châtie les habitants de Séleucie pour être passés du côté d'Antiochos pendant la guerre.

47. Voir Plutarque, Crassus 17, 5 et Dion Cassius 40, I 2.

48. Voir sur ces questions Éd. WILL, HPMH', Nancy, I986, p. 409-410. Voir aussi J. WIESEHÖFER, Ancient Persia from 550 B.C. to 650 A.D., Londres, 2001.

49. Il est difficile de connaître exactement la date à laquelle ce prince s'installe à Suse. G. LE RIDER, op. cit. (n. 35), p. 355-356, pense qu'il régna de I $47 / 6$ à I 40 , date de la conquête parthe. De nouvelles trouvailles monétaires ont cependant contraint les chercheurs, depuis, à faire descendre la date d'accession de Kamniskirès au pouvoir à la toute fin des années I 40, juste avant la conquête parthe (voir Éd. WILL, réf. n. précédente). 
On peut se demander en revanche si c'est bien à Posidonios que remonte cette présentation des événements que l'on trouve dans les Histoires Philippiques selon laquelle les sujets des Parthes accoururent auprès de Démétrios à cause de la cruauté (crudelitatem) du roi des Parthes et parce qu'ils ne supportaient pas la superbia de ce peuple. Cette explication des événements fondée sur une caractérisation négative des Parthes et de la façon dont ils exerçaient leur domination se trouvait-elle dans les Histoires?

La réponse semble aisée pour ce qui concerne le premier point, à savoir la cruauté du roi. Le roi en question est Mithridate I. Or, Mithridate I, chez Posidonios, jouissait d'une excellente réputation. Voici en effet comment le décrit Diodore de Sicile : «Le roi Arsacès, grâce à une politique de clémence

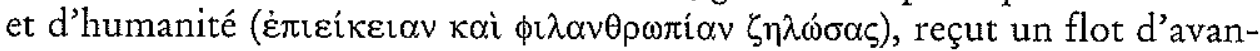
tages et agrandit son royaume : il étendit son pouvoir jusqu'à l'Inde, et, sans une bataille, mit sous sa domination la région autrefois dirigée par Porus; cependant, quoique arrivé à ces sommets de puissance royale, il ne cultiva

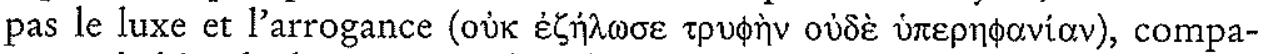

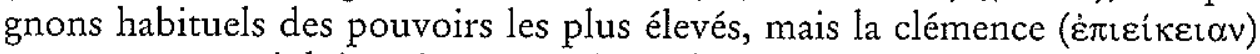
envers ceux qui lui étaient soumis et le courage ( $\left.\dot{\alpha} v \delta \rho \varepsilon_{i} \alpha v\right)$ contre ses ennemis. En somme, après s'être rendu maître de nombreux peuples, il enseigna aux Parthes les meilleures des coutumes pratiquées par chacun. »

Dans son expression, ce portrait de Mithridate est typique du portrait du bon souverain selon Diodore de Sicile (insistance sur la pbilanthropia, l'epieikeia, aspect civilisateur du personnage...) $)^{\text {so }}$ : il est évident qu'il a été totalement réécrit par lui. Il reste que, si Diodore dépeint favorablement Mithridate, c'est que sa source, Posidonios, lui était également favorable. On trouve d'ailleurs des traces, chez Trogue/Justin, de ce portrait positif de Mithridate: au livre 38, l'historien explique ainsi la clémence dont le roi parthe fit preuve envers son prisonnier Démétrios par le fait qu'il avait « une grandeur d'âme toute royale " (magno et regio animo) ${ }^{\text {s. }}$. Trogue/Justin connaissait donc cette tradition favorable à Mithridate.

50. On peut par exemple comparer le portrait de Mithridate I à celui de Zarina, reine des Scythes qui elle aussi accomplit d'importants exploits militaires et civilisa son peuple (voir DS II, 34). Sur l'importance des qualités de civilisateur d'un souverain chez Diodore, voir A.D. SACKS, op. cit. (n. I9), p. 6is.

51. HP $38,9,3$ : «Arsacide, roi des Parthes, qui avait une grandeur d'âme toute royale, l'envoya en Hyrcanie..." " 
On a peine à croire que, après l'avoir décrit comme un bon roi, Posidonios puisse expliquer le ralliement de certaines sujets parthes à Démétrios par la cruauté de Mithridate I ${ }^{32}$. Souvenons-nous aussi que l'historien donnait de Démétrios II un portrait extrêmement sombre, dont le trait principal était la cruauté : pouvait-il vraiment écrire que la domination de Démétrios II, roi cruel et hai du peuple, paraissait aux populations soumises plus agréable que celle de Mithridate I, qu'il décrit par ailleurs de façon positive!

L'idée que les peuples récemment conquis par les Parthes se précipitèrent auprès de Démétrios parce qu'ils ne supportaient pas la cruauté du roi parthe ne provient donc très certainement pas de Posidonios.

Le thème de la cruauté du roi parthe envers ses sujets est en revanche très vivant dans la littérature romaine, au point de devenir un lieu commun. Dès l'époque d'Auguste, les fréquents changements de souverains à la tête du royaume parthe sont compris comme la conséquence de la cruauté de l'Arsacide en place: Trogue/Justin dans son excursus parthe, au livre 42, indique ainsi que Mithridate II, grand homme de guerre (I23-88 av. J.-C.), fut chassé du trône par ses sujets "à cause de sa cruauté " (propter saevitiam) ${ }^{53}$. De même Phraate IV, après avoir assassiné son père et ses trente frères, "se montra si souvent cruel » (cum multa crudeliter consuleret) qu'il fut envoyé en exil par son peuple ${ }^{54}$. Cette interprétation se retrouve très fréquemment chez Tacite - une de nos meilleures sources sur l'histoire intérieure des Parthes. Selon Tacite, en 35 ap. J.-C., des nobles réclamèrent ainsi à Tibère l'otage parthe Vononès $5 s$ afin de remplacer leur roi Artaban, qui montrait « de la cruauté envers ses sujets» (saevitiam in populares) ${ }^{56}$. Ce

52. Cela ne signifie pas que Posidonios considérait l'autorité des rois parthes comme particulièrement douce : les fragments sur les banquets des Arsacides et le rituel sanglant qui leur était associé (le roi flagelle ses amis et leur jette de la nourriture comme à des chiens) montrent au contraire qu'il était sensible à l'aspect despotique du pouvoir royal chez les Parthes (voir Athénée I $52 \mathrm{f}-\mathrm{I} 53 \mathrm{a}=\mathrm{E}-\mathrm{K}$ F. 57 et Athénée 153a-I $53 \mathrm{~b}=\mathrm{E}-\mathrm{K}$ F. 64). Il reste que Mithridate I est décrit chez lui comme un bon roi : ce n'est pas parce qu'un roi respecte une étiquette particulièrement cruelle qu'il est cruel envers ses sujets.

53. Trogue/Justin $42,4,1$.

54 . Trogue/Justin $42,5,4$.

55. En 20 av. J.C., le roi Phraate IV avait envoyé en otages à Auguste neuf de ses fils et petitsfils, en signe d'amitié. Ces otages restèrent ensuite à Rome et $\mathrm{y}$ firent souche.

56. Tacite, Annales 6, 3 I, I. 
même Artaban est qualifié plus loin de « cruel » (regem saevum) 57 , et Tacite rappelle que les Parthes le «détestaient pour sa cruauté 》 (ob saevitiam exsecrati) ${ }^{58}$. Quelques années plus tard, en $42-43$, les Parthes appellent Vardanès au pouvoir car le roi Gotarzès, « entre autres mesures cruelles » (inter pleraque saeva), avait fait périr de nombreux membres de sa famille 59 . Ce Vardanès est rapidement éliminé par ses sujets parce que le succès l'avait rendu "d'autant plus fier et insupportable à ses sujets" (eo ferocior et subiectis intolerantior) ${ }^{60}$, mais Gotarzès, qui alors remonte sur le trône, se fait aussitôt haïr «par sa cruauté et ses excès " (per saevitiam et luxum) ${ }^{61}$.

Le topos de la cruauté du roi parthe remplace très clairement, chez Tacite, toute analyse des rapports politiques au sein du royaume des Arsacides. En réalité, ce topos était largement exploité à Rome et, sous le HautEmpire, l'instabilité des Arsacides et la cruauté de leurs rois - deux phénomènes indissociables - étaient constamment opposées à la stabilité et à la douceur $\mathrm{du}$ pouvoir romain. On en a une illustration très frappante dans le récit que donne le même Tacite d'une entrevue entre des envoyés parthes et l'empereur Claude qui eut lieu en $47:$ des nobles parthes désireux de se débarrasser du roi Gotarzès, « qui cherchait à dissimuler sa cruauté sous sa lâcheté », vinrent en effet trouver Claude pour lui demander de leur envoyer un des petits-fils de Phraate, lui assurant que «s'ils donnaient en otages (aux Romains) des fils de rois, c'était afin de pouvoir, quand une oppression intérieure lasserait leur patience, avoir recours au prince et au sénat pour appeler à eux un roi formé à notre école et meilleur » (...ut... sit regressus ad principem patresque, quorum moribus adsuefactus rex melior adscisceretur) ${ }^{62}$.

L'empereur, flatté, leur cède Méherdatès, auquel il conseille alors « de penser non en termes de domination et d'esclaves, mais en chef à l'égard de citoyens, et de s'adonner à la clémence et à la justice, d'autant plus agréables aux barbares qu'elles leur étaient inconnues » (...ut non dominationem et servos, sed rectorem et cives cogitaret, clementiamque ac justitiam, quanto ignota barbaris tanto gratiora, capesseret).

57. Tacite, Annales, 6, 36 .

58. Ibid., 6, 4I, 2.

59. Ibid., II, 8,2 .

6o. Ibid., II, 10, 3

6I. Ibid., Ix, 10, 4

62. Ibid., I 2, 10, 2. 
Il comble ensuite d'éloges le nourrisson de Rome (alumnum Urbis), "qui avait fait preuve jusque là d'une telle modération (modestia) » et enjoint aux délégués parthes de "supporter le caractère des rois ", car l'on ne gagnait rien aux fréquents changements et "l'État romain, rassasié de gloire, avait atteint une telle élévation qu'il souhaitait aussi le repos des nations étrangères ».

On ne sait si les nobles parthes avaient vraiment développé dans leur discours le thème de l'opposition entre les princes formés à l'école romaine et ceux qui avaient été élevés chez eux ; s'ils le firent, il est évident que c'était pour flatter les Romains, parce qu'ils savaient que rien ne leur serait plus agréable que d'entendre vanter la mansuétude de leurs coutumes et celle de leurs empereurs. La réponse de l'empereur en revanche et les conseils de gouvernement qu'il donne à Méherdatès sont sans aucun doute véridiques et indiquent clairement que les Romains faisaient usage, face aux Parthes, de la dichotomie que les Grecs avaient établie entre eux et les Perses : liberté et clémence d'un côté, servitude et cruauté de l'autre ${ }^{63}$.

Or, on sait que les Romains cherchèrent tout au long du rer siècle à imposer un de leurs otages arsacides sur le trône des Parthes et qu'ils tentèrent plusieurs fois par la suite de conquérir leur royaume: le passage de Tacite que nous venons d'analyser indique que le thème de l'opposition entre les deux types de régime était abondamment exploité dans le cadre de cette rivalité, et c'est la raison pour laquelle il connut un tel succès.

Dans ce contexte, le recours au thème de la cruauté du roi parthe pour expliquer les soutiens obtenus par Démétrios au début de sa campagne parthique me semble trahir de façon quasi certaine le milieu romain dans lequelles ont été composées les Histoires Philippiques: Trogue/Justin utilise un cliché commode, facile et bien installé dans les mentalités parce que souvent utilisé dans le cadre de la lutte entre Parthes et Romains. Ce cliché vient se substituer à la vision positive que les sources avaient transmise de Mithridate I, ce roi particulier s'effaçant devant l'archétype du roi parthe.

63. On trouve d'autres exemples de cette attitude chez Tacite. L'historien explique ainsi que Vononès, otage romain qu'Auguste avait renvoyé chez lui sur demande de nobles parthes, s'était fait rapidement détester de ses concitoyens à cause de "son abord facile et son amabilité prévenante" (prompti aditus, obvia comitas), qualités inconnues aux Parthes et en lesquelles ils voyaient des défauts (Ann. 6, 4I, 2). Par ailleurs, en 36, un autre otage romain envoyé contre Artaban remporta quelques succès contre son rival car, selon Tacite, " les Parthes espéraient (de lui) des dispositions bienveillantes dues à la culture romaine " (... come Tiridatis ingenium Romanas per artes sperabant) (Ann. 6, 4I, 2). 
La question qui se pose est bien évidemment celle de savoir si cette interprétation de l'attitude des peuples soumis aux Parthes au prisme de la cruauté du roi revient à Trogue ou à Justin. Il est difficile d'avoir sur ce point une certitude absolue : l'opposition entre la douceur de la domination romaine et le despotisme parthe, que nous voyons fortement affirmée chez Tacite, est probablement aussi vivace sous Auguste et Tibère qu'à la fin du II ${ }^{c}$ siècle - on sait que Septime Sévère en 197 lance une nouvelle expédition contre les Parthes : l'antagonisme entre Parthes et Romains ne peut qu'en être ravivé. Un élément cependant me paraît significatif, lié au point que nous avons développé plus haut sur le portrait de Démétrios II. La version des événements que proposent les Histoires Philippiques ne fonctionne que parce que le roi Démétrios II n'est pas décrit dans cette œuvre comme un roi sanguinaire et cruel, mais comme un être indolent et mou : le ralliement de tout une partie de la population peut en effet s'expliquer, dans ces conditions, par le contraste que présente le Séleucide avec un roi parthe cruel. Or, nous avons établi plus haut que cette présentation du Séleucide, contraire à celle de Posidonios, remontait de façon certaine à Justin : il en découle que la thèse selon laquelle les peuples d'Orient se précipitèrent auprès de Démétrios II par haine de la cruauté du roi parthe provient elle aussi de Justin. Mollesse de Démétrios, cruauté du roi parthe, ces deux éléments sont inséparables l'un de l'autre et c'est bien le contraste que présentent les deux souverains qui permet à Justin d'expliquer les ralliements que reçut le Séleucide au début de sa campagne.

Il me semble donc que Justin, dans son récit de l'expédition de Démétrios II, substitue à l'analyse complexe qu'il trouvait chez Trogue une version des événements fondée sur un cliché très ancré à Rome au sujet des Parthes : celui de la cruauté de leurs rois. Ce cliché entre en contradiction avec l'image positive que les sources anciennes offraient de Mithridate I mais il a une telle force qu'il vient se substituer à cette image et en efface presque complètement le souvenir. Pour qu'il fonctionne de façon plus efficace, Justin modifie l'image de Démétrios II : ce roi présenté par Posidonios comme cruel et détesté de son peuple n'est plus ici que mou ${ }^{64}$. Justin montre

64. Notons que cette modification n'est que provisoire: Démétrios « récupère " en effet lors de son second règne la cruauté que lui prêtaient Posidonios et Diodore puisque, à cause de "sa fréquentation avec le cruelle nation des Parthes" (conversatione Parthicae crudelitatis), il se montre alors d'un orgueil (superbia) intolérable à son peuple; il se fait d'ailleurs rapidement chasser. Voir Trogue/Justin $39, x, 3$. 
ainsi combien il est influencé par le contexte romain dans lequel il écrit : il relit l'histoire des guerres entre Parthes et Séleucides à la lumière des relations romano-parthiques et emploie pour la raconter les thèmes développés à Rome dans le contexte de la rivalité avec les Parthes. Il est remarquable que, dans cette relecture romaine de la guerre parthique de Démétrios, ce soit les Séleucides qui jouent le rôle des Romains : c'est un Séleucide auprès duquel les peuples soumis aux Arsacides accourent pour demander secours, comme s'il représentait ce monde de liberté que les Romains se targuent d'incarner face aux Parthes. Cette identification entre Séleucides et Romains est surprenante, au vu de l'image très négative que donnent des Séleucides les sources gréco-romaines, notamment du point de vue politique : l'identité romaine s'est construite, dans une large mesure, contre les Gréco-Macédoniens, dont l'image à Rome reprend très largement les thèmes développés par les Grecs de l'époque classique au sujet des Perses. Il apparaît cependant, dans le texte de Justin, que face aux Parthes, l'ennemi absolu, les Romains se reconnaissaient avec les Gréco-Macédoniens une identité commune: les nouveaux Perses, dans ce contexte, ce ne sont plus alors les Séleucides mais les Parthes, par un glissement d'identification.

L'hypothèse d'une reconstruction romaine du récit de l'expédition de Démétrios II est renforcée par la seconde raison qu'invoque Trogue/Justin pour expliquer les ralliements à Démétrios, à savoir le fait que les peuples nouvellement conquis, "dès longtemps habitués au joug des Macédoniens, supportaient difficilement l'arrogance (superbia) de leurs nouveaux maîtres" (novi populi superbiam indigne ferabant). Ce terme de superbia, que l'on traduit en français par «orgueil» ou «arrogance», est chargé en latin d'un sens politique lorsqu'il s'applique à un dirigeant (quelle que soit la nature de son pouvoir) ou à un groupe de personnes exerçant le pouvoir sur d'autres : il devient alors quasiment synonyme d' « autorité excessive ", de «tyrannie ». Chez Tite Live on voit ainsi une femme victime de Philippe V inciter ses enfants à fuir la « superbiam regiam », c'est-à-dire la « tyrannie du roi » ${ }^{6 \xi}$, et Trogue/Justin fait de la superbia de Démétrios I la raison pour laquelle il était détesté de son peuple ${ }^{66}$. Salluste fustige également la superbia

65. Tite Live $40,4, x$.

66. Trogue/Justin 36, I, I ; 36, 1, 9. Après son retour de chez les Parthes, Démétrios II est lui aussi rempli de superbiam et se fait chasser à son tour : voir $39,1,3$. 
de la nobilitas romaine ${ }^{67}$ et Trogue/Justin celle des Quatre Cents à Athènes, qui ne tardent pas à "s'arroger le pouvoir sans limites d'un tyran " ${ }^{68}$.

Or, dans ce sens, la superbia apparaît très fréquemment dans les textes en association avec la cruauté (crudelitas ou saevitia): l'alliance des deux termes sert à caractériser les comportements tyranniques. Les exemples sont innombrables chez les auteurs latins à partir de la fin de la République : cruauté et orgueil fonctionnent en couple et constituent les deux attributs obligés de celui qui agit en tyran, qu'il s'agisse d'un gouverneur romain, d'un magistrat ou d'un empereur ${ }^{69}$.

Le rapprochement entre la «cruauté » du roi des Parthes et la superbia de ce peuple trahit donc de toute évidence un auteur latin. L'alliance entre les deux termes présente les Parthes comme exerçant sur les populations qui leur sont soumises un pouvoir de type tyrannique. La mention de la cruauté du roi parthe provenant de Justin, comme nous avons tenté de le montrer, il est probable que la présence du thème de la superbia est également l'effet d'une intervention de l'abréviateur.

On peut faire à propos de la superbia des Parthes une autre remarque. Contrairement à ce que I'on pourrait penser, l'idée selon laquelle les populations soumises aux Parthes supportent difficilement la superbia de ce peuple n'est pas courante dans la littérature latine ${ }^{70}$ - on n'en a aucun équivalent non plus chez les auteurs grecs. Il n'existe même à ma connaissance qu'un seul parallèle au passage de Trogue/Justin. Il se trouve dans les Annales de Tacite. L'historien évoque l'Arménie, éternelle pomme de discorde entre Parthes et Romains : en 60, alors que les Parthes tentent d'imposer un Arsacide sur le trône arménien, Néron désigne comme prince d'Arménie le Cappadocien Tigrane; parmi les Arméniens, explique alors

67. Voir Salluste, Cat. 20, 9;23,6;33,3 ...

68. Trogue/Justin $5,3,6:$ : comme (les sénateurs), poussés par l'orgueil naturel à leur ordre, sévissaient contre le peuple et comme chacun d'eux s'arrogeait les pouvoirs sans limite d'un tyran..." (Qui cum insita genti superbia crudeliter in plebem consuleret, singulis tyrannidis sibi inpotentiam vindicantibus...).

69. Parmi les nombreuses références, on peut citer Cicéron (voir par exemple Contre Verrès I, 47, I 22) ; Tite Live (8, 33, 10; 8, 33, 13...); Salluste (Cat. 10, 4 ; S I, I4...); Tacite (Ann. I, 4, 3 ; $\mathrm{I}, 72,4$ sur Tibère ; $3,40,4 ; 4,70,3$ sur Séjan...); Suétone, Caligula $34, \mathrm{I}$.

70. L'adjectif superbus est cependant parfois associé aux Parthes: voir Horace, Odes 4, I5, v. 7-8: «... les portes orgueilleuses des Parthes" (Parthorum superbis postibus); Lucain, 8, 215 : "le superbe Arsacide " (superbo Arsacidae). 
Tacite, certains favorisaient le candidat arsacide, mais beaucoup, « exaspérés par l'orgueil des Parthes (superbiam Parthorum perosi), préféraient un roi donné par les Romains ${ }^{7 x}$. Le parallélisme entre la situation décrite dans les Histoires Philippiques à l'occasion de l'expédition de Démétrios II et celle qui est présentée ici par Tacite est très net. Il peut s'agir d'un hasard ; le fait qu'on ne trouve nulle part ailleurs dans la littérature latine de récit similaire et exprimé dans les mêmes termes incite cependant à penser que l'un des deux textes fait directement écho à l'autre. Ce ne serait d'ailleurs qu'un cas parmi d'autres : les études menées sur la langue des Histoires Philippiques ont montré depuis longtemps qu'elle présentait de nombreuses similitudes avec celle de Tacite; or, la question se pose toujours de savoir si on doit reconnaître dans ces similitudes l'effet d'une influence de Trogue sur Tacite, ou de Tacite sur Justin ${ }^{72}$. Dans la mesure où les passages que nous examinons ici portent la trace nette d'une réécriture des événements par Justin, il me semble que, dans ce cas précis, on peut affirmer que c'est bien Tacite qui a influencé le compilateur : Justin, reconnaissant un parallélisme entre la situation des «peuples de l'Orient » de l'époque de Démétrios II face aux Parthes et celle des Arméniens de l'époque de Néron, fait appel pour décrire cette situation à une réminiscence tacitéenne. Que Justin se soit inspiré de Tacite ne fait que renforcer la thèse selon laquelle on trouve dans son résumé des Histoires Philippiques une interpretatio romana des guerres entre Parthes et Séleucides.

On doit conclure de cette longue analyse que le récit de l'exédition de Démétrios contre les Parthes a subi à l'époque romaine, et plus probablement du fait de l'abréviateur Justin, une véritable réécriture. Certes, Posidonios évoquait le soutien apporté au Séleucide par une partie des populations soumises aux Parthes - Gréco-Macédoniens ou «peuples orientaux »; il ne

71. Tacite, Annales 14, 26, 2.

72. Voir l'étude de J.C. YARDLEX, Justin and Pompeius Trogus. A study of the language of Justin's Epitome of Trogus, Toronto, 2003. L'auteur met en valeur un nombre très important de parallèles étroits entre les Histoires Philippiques et les œuvres de Tacite, et considère ces parallèles comme des "Justinisms" (voir p. 11 $4:$ "I do feel it more likely that Justin knew the works of Tacitus - as be did that of Suetonius - and so cite possible Tacitean influences on Justin amongst the "Justinisms"). Contra, voir F.R.D. GOODYEAR, "On the Character and Text of Justin's Compilation of Trogus ", Proc. of the African Classical Association, 16, 1982, p. 1-24 (=F.R.D. GOODYEAR, Papers on Latin Litterature, choisis et édités par K.M. Coleman, J. DigGle, J.B. Hall et H.D. JOCELYN, Londres, 1992, p. 2 10-233). 
l'expliquait cependant pas de la façon dont le fait Trogue/Justin. On ne peut que regretter de ne pas connaître sa version des événements, qui nous aurait appris beaucoup sur une image grecque des Parthes à cette époque... mais il est impossible de la reconstruire. Quant à la réinterprétation romaine, elle s'explique à la fois par le souci de simplification de Justin et par l'importance qu'ont prise les Parthes dans la vie politique et militaire romaine après la bataille de Carrhes: des événements aussi anciens que les campagnes des Séleucides sont relus à la lumière des guerres entre Parthes et Romains, ellesmêmes vues sur le modèle des Guerres Médiques. Il est notable de constater que les Romains s'identifient, de ce fait, aux Séleucides, qu'ils critiquent vertement par ailleurs: face aux Parthes, les Gréco-Macédoniens, souvent décrits comme des Perses, redeviennent des Grecs et la parenté entre Romains et Gréco-Macédoniens semble ressortir, par un effet de contraste.

\section{La captivité de Démétrios II}

La captivité de Démétrios II, dont Posidonios faisait le récit, constitue le second épisode important des relations entre Parthes et Séleucides au second siècle. Trogue/Justin, la source la plus développée sur ce sujet, insiste sur le bon traitement que reçut le roi pendant ces dix années passées chez les Parthes : il fut, indique-t-il au livre 36, "traité avec douceur et eut un train de maison conforme à son ancienne fortune »; il écrit également, au livre 38 , que l'Arsacide «fournit (à Démétrios) un train de vie digne d'un roi » (cultum regium praestitit) ${ }^{73}$. Cette information remonte de façon certaine à Posidonios : d'après Athénée en effet, Posidonios, au livre 16 des Histoires, racontait "qu'après être monté en Médie et avoir fait la guerre à Arsacès, (Démétrios) fut fait prisonnier par le barbare et passa un long moment chez

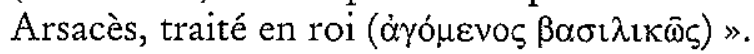

Dans la mention que fait Trogue du «train de vie royal » que Phraate accorda à Démétrios, on doit reconnaître un écho du texte de Posidonios selon lequel Démétrios fut «traité en roi ».

Trogue explique en outre que le roi Mithridate avait donné sa fille en mariage à Démétrios 74. D'après Appien, qui lui aussi évoque rapidement la captivité de Démétrios II, ce ne serait pas Mithridate qui aurait donné sa fille 
à Démétrios, mais Phraate II qui lui aurait donné sa sœur Rodogune 75 . On sait cependant combien ce type de détail est sujet à déformation : de la différence entre Trogue et Appien on ne peut tirer nulle conclusion sur l'identité que Posidonios attribuait à cette femme. Retenons simplement qu'il évoquait le mariage entre Démétrios et une femme apparentée de près au roi parthe.

Trogue associe en outre à l'évocation de la captivité de Démétrios, qu'il situe en Hyrcanie, une série d'anecdotes ${ }^{76}$. Démétrios selon lui, quoique traité somptueusement, se serait rapidement ennuyé de la vie de simple particulier qu'il menait chez les Parthes. Son ami Callimandre étant parvenu à le rejoindre depuis la Syrie, déguisé en Parthe, Démétrios aurait tenté à deux reprises de s'évader en sa compagnie. Phraate, la première fois, l'aurait sévèrement réprimandé et soumis à une garde plus rigoureuse, tout en récompensant Callimandre pour sa fidélité ; la seconde fois, il aurait refusé de l'admettre en sa présence et aurait offert au roi des osselets d'or, pour lui faire honte de sa "légèreté puérile »; il lui aurait cependant fait grâce, en faveur de sa femme et de ses enfants. Cette clémence de Phraate pour Démétrios, remarque Trogue en conclusion, ne venait pas, en réalité, « de la pitié de ce peuple ni d'égards pour sa parenté avec eux, mais de leur désir de s'emparer du royaume de Syrie (sed quod Syriae regnum adfectabant) : ils voulaient se servir de Démétrios contre Antiochos, son frère, selon que l'exigeraient la situation, la circonstance ou la fortune de la guerre ».

Il est évident que, dans le récit des différentes tentatives d'évasion de Démétrios II, l'on a affaire à un développement de type romanesque : la figure de Callimandre, l'ami fidèle, dont Trogue explique qu'il avait «traversé les déserts de l'Arabie avec des guides soudoyés ", déguisé en Parthe, appartient bien davantage au registre du roman qu'à celui de l'histoire, tandis que l'aspect moralisateur de Phraate II, qui félicite Callimandre pour sa fidélité et offre des osselets d'or à Démétrios, donne au récit l'aspect d'une de ces anecdotes édifiantes qu'affectionnent les historiens antiques. Il n'y a d'ailleurs rien de surprenant à ce qu'au fil du temps se soient développées au sujet de la longue captivité du roi chez les Parthes des anecdotes n'entretenant plus qu'un rapport lointain avec la réalité. 
LES GUERRES ENTRE PARTHES ET SÉLEUCIDES

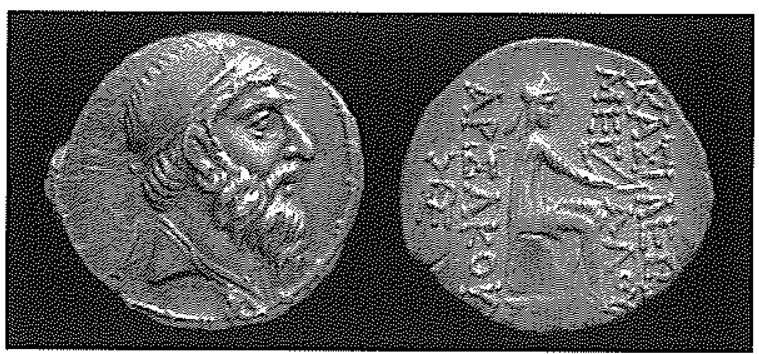

FIG. I. - Drachme de Mithridate I (I $7 \mathrm{I}-138$ av. J.-C.) Au revers: Arsacès portant un arc, assis sur l'omphalos (Louvre, cabinet des Médailles n. 1972-42).

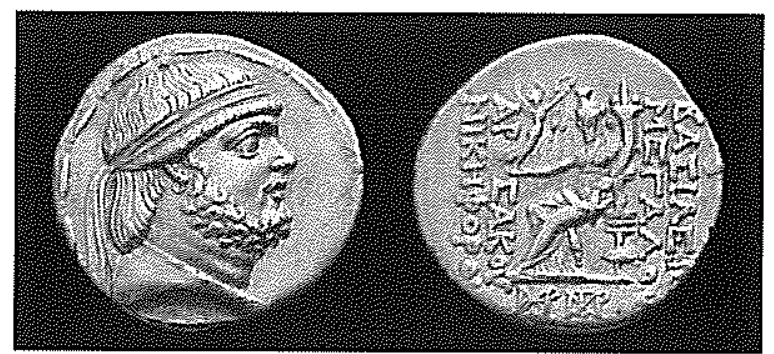

FIG. 2. - Tétradrachme de Phraate II ( $138-127$ av. J.-C.). Au revers : dieu barbu portant une Victoire et une corne d'abondance. Voir G. LE RIDER, Suse sous les Séleucides et les Parthes, Paris, I965, pl. 70, 26.

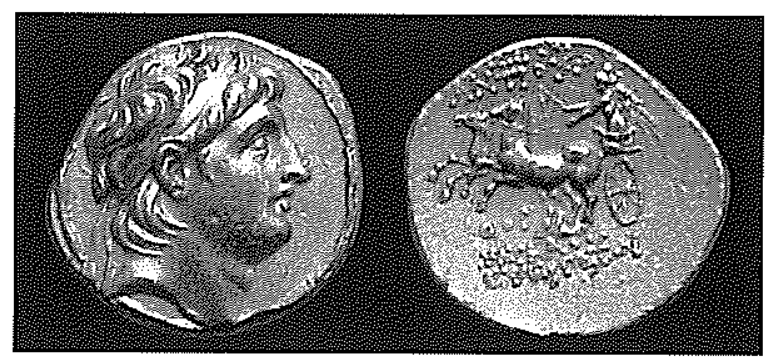

FIG. 3. - Statère d'Antiochos VII (138-I29).

Au revers : Victoire ailée montée sur un char.

Monnaie publiée par Ch. Houghton, "A victory coin and the Parthian Wars of Antiochus VII", Proceedings of the $9^{\text {th }}$ International of Numismatics, I986, IAPN Publications n. I I, pl. 6. D'après l'auteur, cette monnaie, datée de $134-133$, pourrait célébrer une victoire remportée cette année-là par Antiochos VII sur les Parthes et inconnue des sources littéraires. 
On n'a aucune raison de penser que le récit de la captivité de Démétrios tel que le présente Trogue ne provient pas de Posidonios. Un fragment transmis par Athénée semble même renforcer cette hypothèse. On est frappé en effet, lorsqu'on lit le récit de Trogue, du fait que le roi parthe Phraate paraît bien plus sage que le Séleucide : Phraate récompense la fidélité de Callimandre et critique la légèreté puérile de Démétrios, tandis que celui-ci ne songe qu'à s'enfuir parce qu'il veut redevenir roi et s'ennuie chez les Parthes. Or, dans un passage relatif à l'expédition malheureuse d'Antiochos VII, Posidonios prête au roi Phraate, au moment où il enterre le roi, les paroles suivantes: "Ta hardiesse ( $\theta \dot{\alpha} \rho \sigma o \varsigma)$ et ton ivrognerie ( $\mu \varepsilon \dot{\theta} \theta \eta)$ t'ont perdu, Antiochos, car tu as espéré boire la royauté d'Arsacès dans de grandes coupes. 77 »

On retrouve, dans ce fragment, un roi parthe moralisateur face à un Séleucide présenté comme déraisonnable: de même que Démétrios, chez Trogue, était léger et inconstant, de même Antiochos apparaît ici comme faisant preuve d'une hardiesse irréfléchie et d'ivrognerie. Le ton est similaire dans les deux passages et incite à penser que Posidonios est bien la source de Trogue ${ }^{7}$. Cela pourrait signifier que Posidonios marquait une opposition entre les Séleucides, qu'il décrit la plupart du temps comme débauchés et grands amateurs de boisson, et les Parthes, dont le mode de vie les rendait plus propres à la guerre: cette opposition servirait à expliquer les succès remportés par les Parthes sur les Séleucides. En tout cas, Strabon et Trogue, les deux historiens à s'être le plus intéressés aux débuts des Parthes et tous deux lecteurs de Posidonios, insistent l'un et l'autre, dans les chapitres qu'ils ont consacrés aux Parthes, sur leurs qualités militaires, leur endurance et le courage qui leur ont permis, à partir d'un petit territoire montagneux, de devenir les maîtres d'un grand empire 79 : il est fort probable qu'ils ont hérité de Posidonios ce schéma d'explication.

77. E-K F. G3.

78. Voir E. SAlomone, Fonti e valore storico di Pompeo Trogo (Iustin. XXXVIII 8, 2-40), Gênes, I973, p. 63.

79. Voir l'excursus parthe de Trogue aux livres $4 \mathrm{I}$ et 42 : le courage militaire (virtus) des Parthes est fréquemment rappelé $(4 \mathrm{I}, \mathrm{I}, 6 ; 4 \mathrm{I}, 5,7 ; 4 \mathrm{I}, 5,10 ; 42,2,4) ;$ les Parthes sont en outre "sobres de nourriture" $(4 \mathrm{I}, 3, \mathrm{IO})$ et ne font usage de l'or et de l'argent que pour leurs armes $(4 \mathrm{I}, 2,10)$. Voir également Strabon, selon lequel les Parthes doivent leurs conquêtes à leur "genre

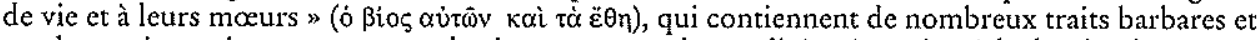
scythes mais aussi, pour une part plus importante, "les qualités nécessaires à la domination et aux

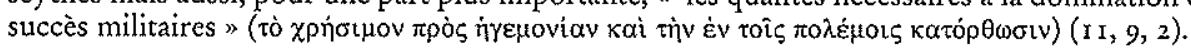


Quant à l'explication que Trogue donne à la bienveillance manifestée par les rois parthes envers Démétrios, qui était provoquée avant tout, selon lui, par leur «désir de s'emparer du royaume de Syrie» (quod Syriae regnum adfectabant), elle provient également de Posidonios. D'après Diodore de Sicile en effet, après sa victoire sur Antiochos VII, «Arsacès, le

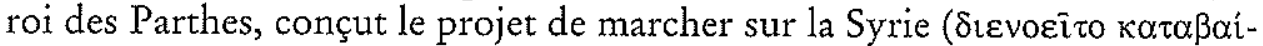

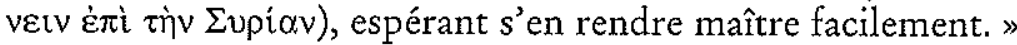

Posidonios prêtait donc bien aux Parthes le désir de se rendre maître de la Syrie et on ne doit pas voir dans ce passage des Histoires Philippiques l'effet d'une projection romaine.

\section{L'expédition d'Antiochos VII}

Le dernier épisode des campagnes menées par les Séleucides contre les Parthes au second siècle est constitué par l'expédition que lança Antiochos VII afin de délivrer son frère en I30/I29. Contrairement à celle de Démétrios, la campagne d'Antiochos est documentée par un certain nombre de fragments de Diodore de Sicile : la comparaison entre le texte de Diodore et celui de Trogue est donc possible, ce qui rend la reconstitution des propos de Posidonios plus aisée. On trouve également de brèves mentions de la campagne d'Antiochos chez Flavius Josèphe $(A J$ I3, 249-25I) et chez Appien (GS 68).

Selon Trogue, Antiochos aurait entrepris la guerre contre les Parthes parce qu'il savait que ces derniers avaient l'intention d'utiliser son frère contre lui. L'armée qu'il emmena avec lui était aguerrie mais vivait dans un luxe sans pareil : les boulangers et cuisiniers y étaient plus nombreux que les soldats eux-mêmes ( 300000 contre 80000 ), et l'or et l'argent étaient tellement abondants que les simples soldats mettaient des clous d'or à leurs souliers et foulaient «cette matière si désirée des hommes qu'ils se la disputent par le fer ». Les ustensiles de cuisine étaient d'argent, "comme s'ils se rendaient à un festin, non à la guerre». À son arrivée, Antiochos reçut la soumission de "plusieurs rois orientaux maudissant l'orgueil des Parthes" (multi orientales reges... cum exsecratione superbiae Parthicae) et parvint à occuper toute la Babylonie, recevant ainsi le surnom de "Grand ». Alors, explique Trogue, « tous les peuples passent à son parti et il ne reste plus aux Parthes que le territoire de leurs pères (patrios fines) ». Phraate envoie Démétrios en Syrie afin de créer une diversion, sans succès. Antiochos VII cependant doit faire hiverner ses troupes, tellement nombreuses qu'il est contraint de les disperser 
dans plusieurs cités. Or, l'entretien de cette armée est bien trop lourd pour les cités en question: accablées par la fourniture des vivres et en butte aux violences des soldats, elles passent de nouveau aux Parthes. Antiochos livre alors bataille au roi parthe; il combat courageusement mais ses soldats, eux, ne font preuve d'aucune bravoure. Le roi séleucide est tué et reçoit de la part de Phraate des obsèques royales. Phraate épouse la fille de Démétrios, qu'Antiochos avait emmenée avec lui. Il tente ensuite de rattraper Démétrios, se repentant de l'avoir laissé partir, mais il n'y parvient pas et renonce à ce projet. Enfin, au début du livre 39, Trogue évoque brièvement la douleur qui s'empara de toute la Syrie à l'annonce de la défaite du roi ${ }^{\text {so }}$.

Sur le déroulement des événements, les fragments de Diodore et le récit de Trogue/Justin présentent de nombreux points communs; on peut donc considérer que leur version des événements est conforme, dans ses grandes lignes en tout cas, à celle que l'on trouvait chez Posidonios. Diodore comme Trogue présentent Antiochos comme vainqueur dans un premier temps ${ }^{81}$; tous deux décrivent ensuite la douleur des Syriens à l'annonce de la mort du roi ${ }^{82}$. Certes, Diodore évoque précisément la douleur des habitants d'Antioche, dont il énumère les différentes manifestations, tandis que Trogue évoque le deuil de «toute la Syrie»; cette inexactitude n'est cependant qu'un effet de l'aspect abrégé du texte - qu'on l'impute à Trogue ou à Justin. L'idée selon laquelle Antiochos perdit le soutien des cités grecques à cause de la lourdeur des dépenses que leur imposait l'entretien de l'armée et des violences des soldats se retrouve également chez Diodore qui dans un fragment évoque Athénaios, un général d'Antiochos «qui s'était rendu coupable d'injustices en logeant ses soldats » et finit par mourir de faim après la victoire des Parthes, car aucun des villages «qu'il avait mal traités pour donner des quartiers à ses soldats » ne voulut le recevoir ${ }^{83}$. Enfin, Diodore comme Trogue reconnaissent que le roi Antiochos VII fit preuve dans sa guerre contre les Parthes d'un réel courage sur le champ de bataille ${ }^{8_{4}}$.

8o. Trogue 39, I, I : « Toute la Syrie était dans le deuil à cause de la destruction de l'armée. "

81. Diodore $33 / 34$, I 5 .

82. Diodore $33 / 34,17, \mathrm{I}$; Trogue Justin 39, I, I.

83. Diodore $33 / 34,17,2$.

84 . Diodore $33 / 34$ I6: Antiochos, n'ayant pas voulu écouter ses amis qui lui déconseillaient de se battre, "attendit avec courage l'arrivée des ennemis». Trogue/Justin 38, 10, $9:$ Antiochos combattit "avec un courage que ses soldats n'imitèrent pas" (fortius quam exercitus ejus dimicavit). 
Diodore et Trogue suivent donc, de toute évidence, la même source. Il semblerait même qu'on trouve chez Trogue un écho textuel d'un passage de Diodore de Sicile : selon Diodore, Antiochos VII, après ses premiers succès, aurait fait dire aux Parthes qu'il n'accepterait la paix que si le roi abandonnait les territoires qu'ils avaient enlevés et, « ne gardant que son territoire

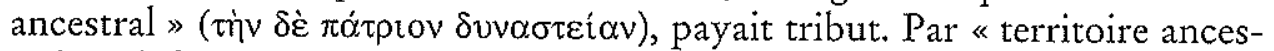
tral », il faut comprendre la Parthyène, région dans laquelle les Parnes s'étaient installés au $\mathrm{III}^{\mathrm{c}}$ siècle $^{8}$ s. Or, Trogue de même affirme que les Parthes, au terme de la première campagne d'Antiochos, ne possédaient plus que leur "patrios fines », le territoire de leurs pères : l'expression latine sonne nette-

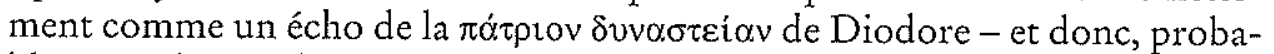
blement, de Posidonios. Certes, lorsque Trogue (ou Justin!) affirme que les Parthes en I 29 furent effectivement refoulés dans le territoire de leurs pères, il confond le discours séleucide et la réalité. Il reste que l'expression provient très certainement de sa source grecque.

On ne possède pas en revanche de fragment de Diodore consacré au luxe de l'armée d'Antiochos. La description de Trogue paraît cependant en plein accord avec un certain nombre de fragments de Posidonios vilipendant le luxe des Séleucides et de leurs sujets : un fragment évoque ainsi la magnificence des banquets qu'offrait Antiochos VII à ses invités ${ }^{86}$, tandis que dans un autre, Posidonios fustige le luxe des habitants des cités syriennes qui passent leur temps à festoyer, à boire du vin et à jouer de la flûte ${ }^{87}$. Il est donc tout à fait vraisemblable que l'historien grec donnait du roi et de son armée une description similaire à celle que l'on trouve chez Trogue.

Enfin, dans ce récit comme dans celui qu'il consacre à Démétrios, Trogue, pour expliquer le ralliement à Antiochos de nombreux rois orientaux (multi orientales reges), invoque le fait qu'ils « maudissaient l'orgueil des Parthes » (cum exsecratione superbiae Parthicae). La similitude entre les deux schémas laisse peu de doutes sur le fait que l'on se trouve ici face à un redoublement. L'explication de l'attitude des « rois orientaux » doit être

85. La notation de Diodore indique que le roi Antiochos VII caressait bien l'espoir de récupérer la Mésopotamie et l'Iran et de revenir à la situation qui prévalait avant les conquêtes de Mithridate I.

86. Voir Posidonios, E-K F. 6ra et 6I b.

87. Voir Posidonios, E-K F. 62 a et $62 \mathrm{~b}$. 
imputée, en bonne logique, à Justin, puisque c'est à lui que remonte le récit de l'expédition de Démétrios tel qu'on le trouve dans les Histoires Pbilippiques. Comme pour l'expédition de Démétrios II, il paraît impossible, en l'absence de fragment de Diodore sur ce point, de savoir quelle explication proposait Posidonios des premiers succès d'Antiochos VII.

La conclusion de cette étude est que, même si le récit que proposent les Histoires Philippiques des guerres entre Parthes et Séleucides du $\mathrm{II}^{\mathrm{e}}$ siècle av. J.-C. est inspiré de celui de Posidonios, on ne peut le considérer comme un reflet fidèle de ce dernier : le texte de Posidonios a fait l'objet d'une réécriture romaine partielle, que nous croyons pouvoir imputer à Justin plutôt qu’à Trogue. Cette réécriture est visible à travers les motifs que Trogue/Justin prête à Démétrios II au moment où il lance son expédition parthique ainsi qu'à travers l'explication qu'il offre aux succès remportés par Démétrios et Antiochos VII au début de leurs guerres : rejet de la superbia des Parthes et, dans le cas de l'expédition de Démétrios, de la cruauté de Mithridate I. Cela ne signifie pas que Posidonios avait une vision particulièrement angélique des Parthes ni de leurs rois : deux fragments des Histoires consacrés aux banquets des Arsacides, dont l'analyse ne rentrait pas dans le cadre de cette étude, indiquent qu'il attribuait aux rois parthes des comportements despotiques envers leurs amis nobles qui évoquent de près ceux des Achéménides ${ }^{88}$. Quelques fragments de Diodore évoquent en outre la sévérité avec laquelle Phraate II, aux lendemains de la guerre, punit les cités de Mésopotamie qui avaient soutenu Antiochos VII contre lui (voir Diodore de Sicile 34, I7 et 34, 19). Il reste que Posidonios n'utilisait pas le thème du despotisme des Parthes dans le cadre du récit des guerres avec les Séleucides et surtout, n'en faisait pas un facteur d'explication capable de rendre compte des premiers succès remportés par ces derniers : la vision qu'il propose de Démétrios II, tyran sanguinaire, rend peu plausible une telle explication. Posidonios n'établissait pas de différence entre le despotisme des Séleucides 
et celui des Arsacides. Ce sont les Romains qui, parce qu'ils exploitaient eux-mêmes le thème de l'opposition entre un monde tyrannique, celui des Parthes, et leur propre monde, règne de la liberté et de la clémence, analysèrent en ces termes les guerres entre Parthes et Séleucides et plaquèrent sur elles le modèle des Guerres Médiques, accordant aux Parthes le rôle anciennement joué par les Perses.

La lecture romaine des événements étant la seule à être parvenue jusqu'à nous, on ne peut en dire davantage sur la façon dont Posidonios luimême analysait les premiers succès séleucides et, plus globalement, présentait les rapports entre les Parthes et les populations récemment soumises à leur domination.

On peut affirmer cependant que Posidonios voyait les Parthes comme un peuple puissant et menaçant : on a vu qu'il leur prêtait le désir de s'emparer de la Syrie après avoir vaincu à deux reprises les armées séleucides. On doit mesurer sur ce point l'évolution que marque l'œuvre de Posidonios par rapport à celle de son prédécesseur Polybe (209-126?): chez Polybe, le premier historien grec à évoquer les Parthes, qui apparaissent au cours du récit de l'Anabase lancée par Antiochos III en 2 I 2 dans le but de rétablir l'autorité séleucide sur les satrapies orientales, les Parthes ne sont qu'un petit peuple barbare des confins, facilement vaincus par l'ingéniosité des Grecs ${ }^{8}$. Dans l'œuvre de Posidonios, qui vient après les conquêtes de Mithridate, ils sont devenus une grande puissance rivale des Séleucides - la lecture de Diodore indique cependant qu'Antiochos VII, en I29, caressait toujours l'espoir de reconquérir ses territoires et de confiner les Parthes en Parthyène. Les fragments que nous avons étudiés paraissent indiquer en outre que Posidonios accordait aux Parthes et à leurs roi une certaine sagesse, des qualités dont les Gréco-Macédoniens étaient dépourvus et qui expliquaient probablement les succès militaires qu'ils avaient remportés contre eux : nous retrouvons ce thème d'analyse chez Strabon et dans les livres $4 \mathrm{I}-42$ de Trogue/Justin, consacrés entièrement aux Parthes.

Les Grecs de la fin de l'époque hellénistique avaient donc élaboré une image de ces Parthes qui avaient privé les Séleucides d'une grande partie de leur empire. Il est difficile, en raison du naufrage des sources de cette

89. Polybe, 10, 27-3 I (le texte provient des Excerpta antiqua complétés par des mentions de la Souda et d'Étienne de Byzance). 
période et du rôle important que jouèrent les Parthes tout au long de l'histoire romaine, de retrouver cette image et de la distinguer de celle qui fut ensuite élaborée à Rome : l'exemple des récits des guerres entre Parthes et Séleucides nous a montré que l'interprétation romaine était venue recouvrir en partie la version posidonienne des événements. Une analyse serrée des textes nous a permis cependant de distinguer ce qui revenait à Posidonios et ce qui était le fruit d'une intervention plus tardive. Elle nous a offfert par conséquent des renseignements tant sur Posidonios et sa vision des Parthes que sur les Romains eux-mêmes et les thèmes qu'ils développaient dans le cadre de leur rivalité avec les Arsacides.

Charlotte Lerouge-CoHen 